\title{
الثقافة السياسية كأداة لتحليل تجربة اللامركزية الإدارية \\ في العراق
}

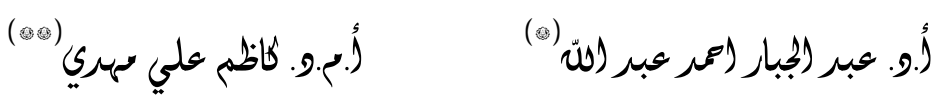

ملخص البحث

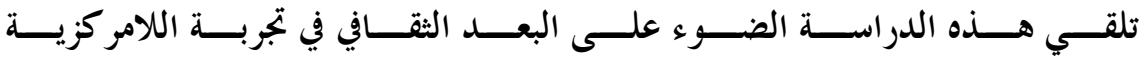

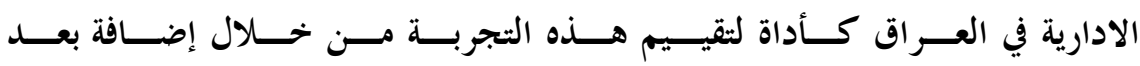

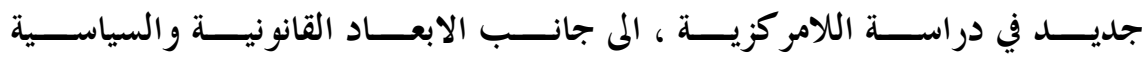

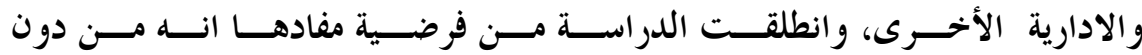

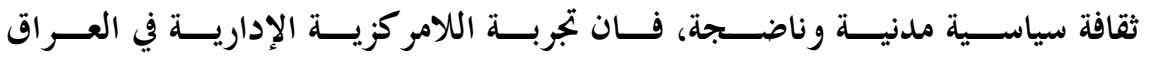

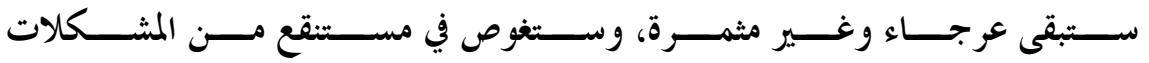

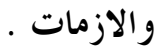

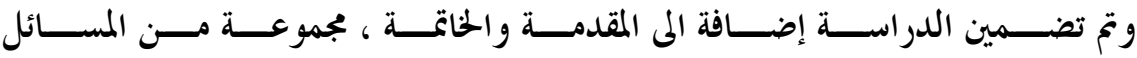

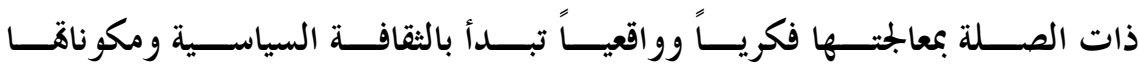

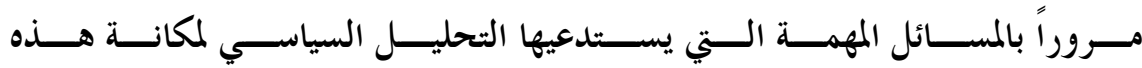

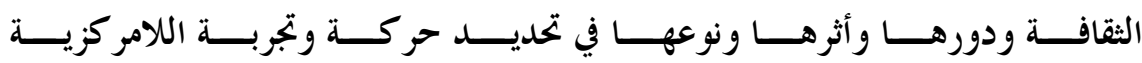

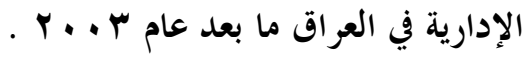

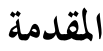

منذ اعتماد اللامركزية السياسية والإدارية كسبيل لإدارة الدولة في شؤوفا السياسية وغير السياسية على مستوى الأقاليم والخافظات، وارتباطها بالفلسفة 
السياسية الديمقراطية الجديدة منذ عام ب... ، خ خضعت هذه التجربة للعديد من

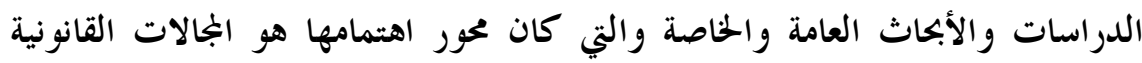
والإدارية والسياسية ، وهي تمثل رصيد غني من الناحية العلمية لدراسة تجربة اللامركزية في العراق والتي للأسف لم تستثمر من صناع القرار والسياسة العامة في وصيدي العراق . الع ل

نحاول ومن خلال هذه الدراسة المتواضعة القاء الضوء على البعد الثقافي في تجربة

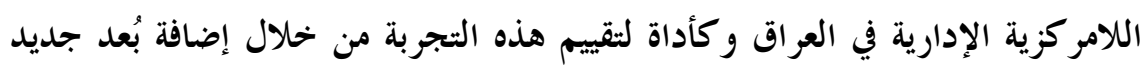

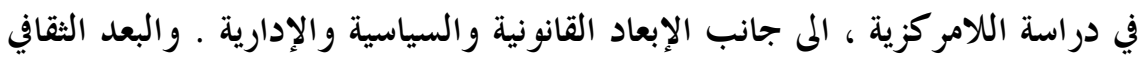

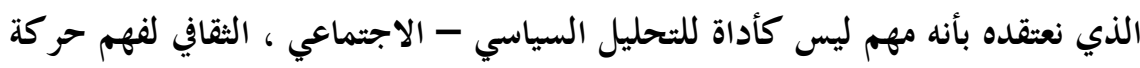

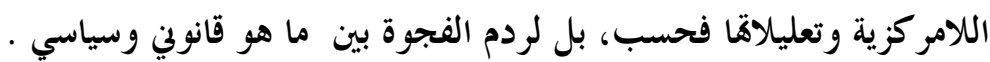

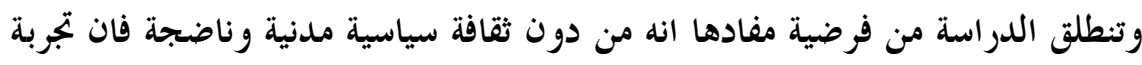
اللامركزية الادارية في العراق ستبقى عرجاء وغير مثمرة وستغوص في مستنقع من المشكلات والأزمات .

سنحاول من خلال هذه الدراسة مراجعة دور وأثر الثقافة السياسية ونوعها في تحديد حر كة وتجربة اللامركزية الإدارية من خحلال مجموعة مسائل وبالتتابع، والتي سنبدأها بالثقافة السياسية ومكوناها والمسائل المهمة التي يستدعيها التحليل السياسي لمكانة الثقافة السياسية ودورها.

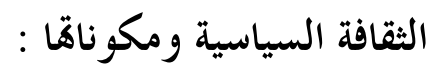
ان الثقافة هي اولاً وقبل كل شيء من صنا : صنع الإنسان وأن ممارستها متباينة كل

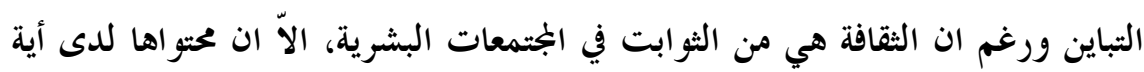

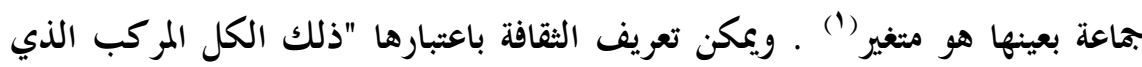

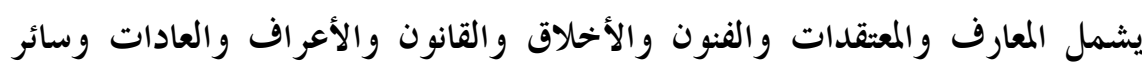

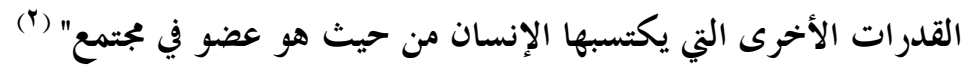


اما الثقافة السياسية بصورة عامة يقصد بها الجوانب السياسية للثقافة معتبرين اها تشكل

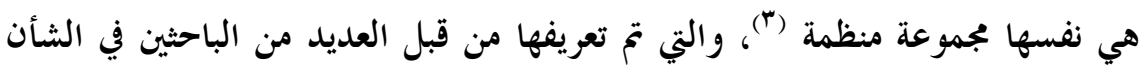
السياسي ومنهم روي مكريدس الذي يرى بأفا "الاهداف المشتر كة والقواعد العامة لهن

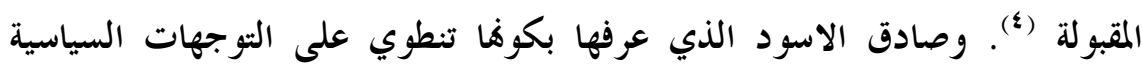

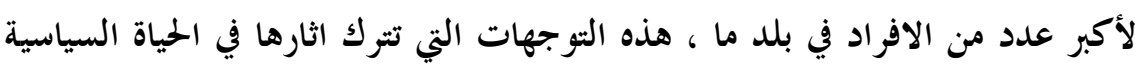

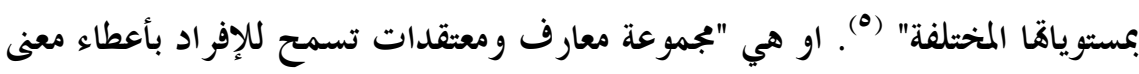

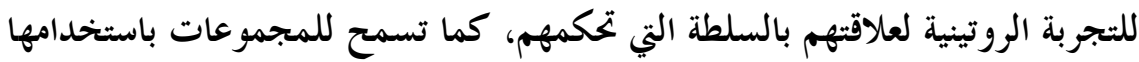

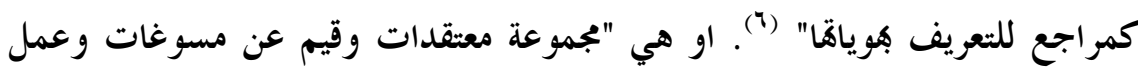

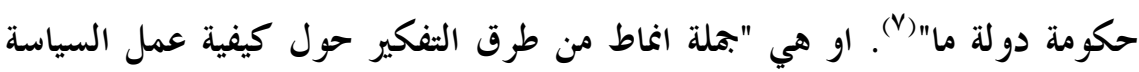

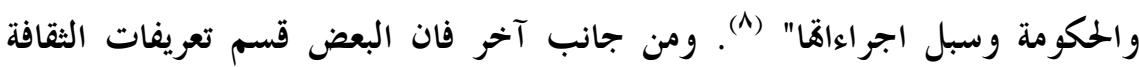
السياسية الى اربعة اقسام وهي التعريفات النفسية التي تنظر للثقافة السياسية على انها

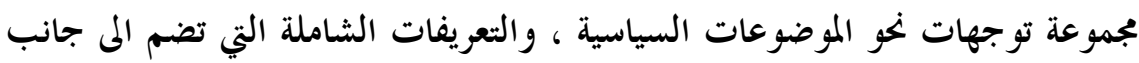

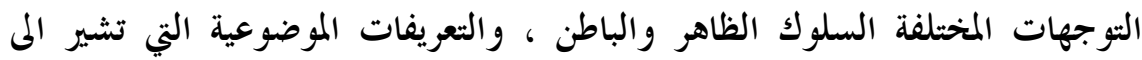
المستويات الخددة للسلوك المقبول من الافراد داخل اي نسق سياسي ، وأخيراً

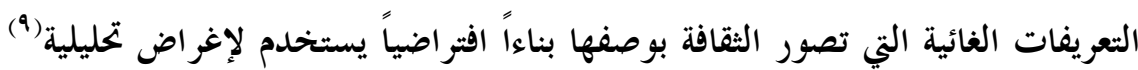

اما العناصر التي تتألف منها الثقافة السياسية ، فيوردها روبرت داهل بما يلي : (•) 1. التوجهات الخاصة بحل المشكلات هل تنحو نحو الزعة البرجماتية ام العقلانية. r. التوجهات نحو السلوك الجمعي هل تتسم بالتعاونية ام اها ليست تعاونية . r. التوجهات نحو النسق السياسي هل تتميز بالولاء ام تتسم باللامبالاة . . ع. التوجهات نحو الاشخاص الآخرين هل تغلب عليها الثقة ام تخلو من الثقة . ويمكن تصور الثقافة السياسية على الها البيئة او المناخ العاطفي او السايكولو جي لهي

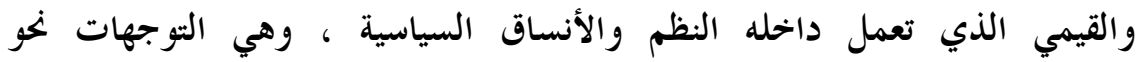

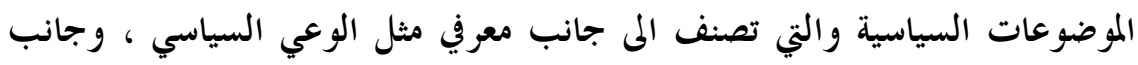


عاطفي مثل الاتجاهات العاطفية وجانب تقويمي مثل الحكم على النسق السياسي .

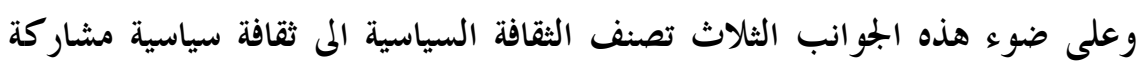
وتابعة ومحدو دة (11). ومن الضروري الإشارة الى ان مقاربة الثقافة السياسية انطلقت مع الدراسة التي قام هـا

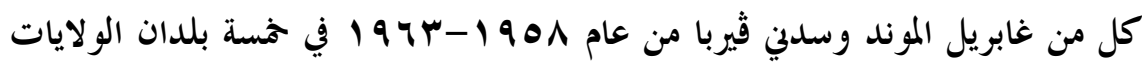

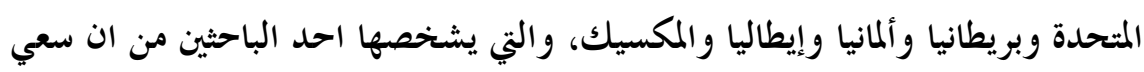

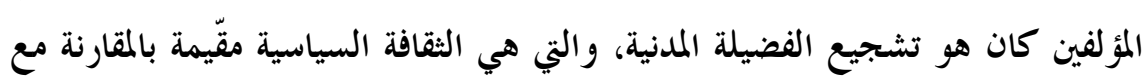
القيم الديمقر اطية(r) (1). واذا اردنا ان نوجر نقول ان جوهر الثقافة السياسية القيم والمعارف والاتجاهات

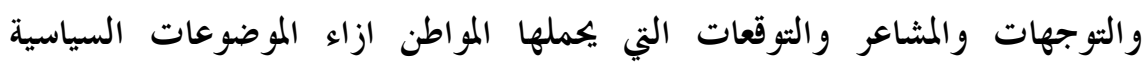

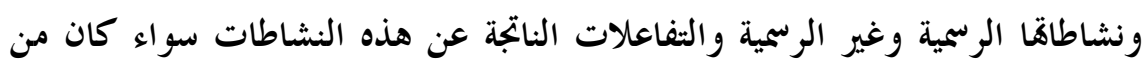
خلال قرارات سياسية او سياسات عامة او تشريعات او مواقف سياسية .

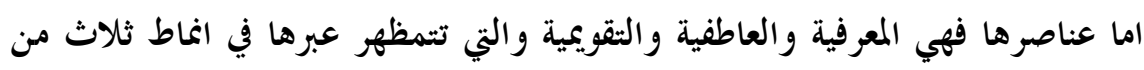

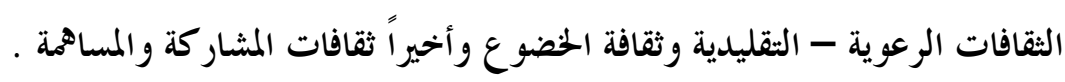

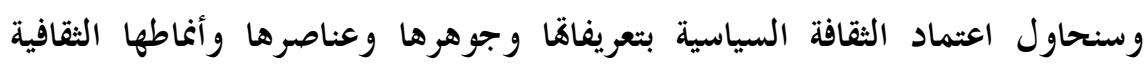

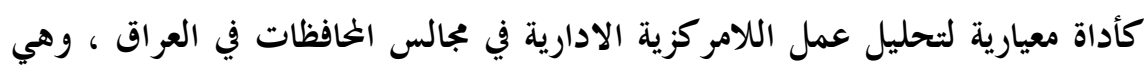

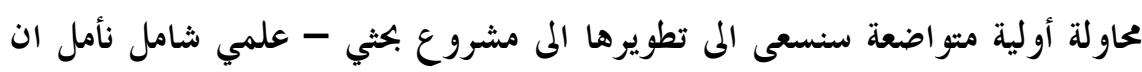
يسهم فيه زملاؤنا في الحقل المعرفي والأكاديمي .

المسألة الاولى : اللامر كزية الادارية هل هي حقد سياسي امدي ام اداري بخلاف المركزية فان اللامركزية تنقسم المى قسمين ، الاول اللامركزية الادارية والتي تعني وحدة التشريع وثنائية التنفيذ ، والثالي اللامركزية السياسية والتي تعني ثنائية

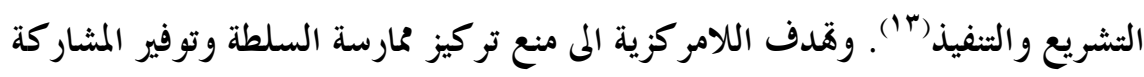

السياسية في البعد الخلي والوطني (محافظات و اقاليم) (؛ ('). 


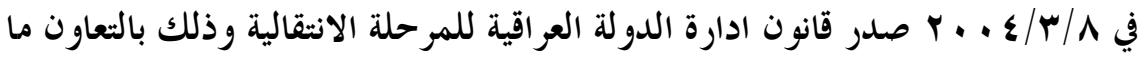

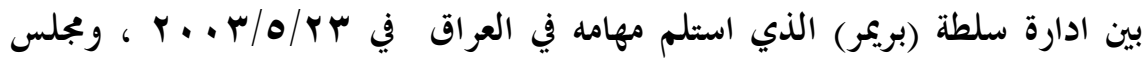

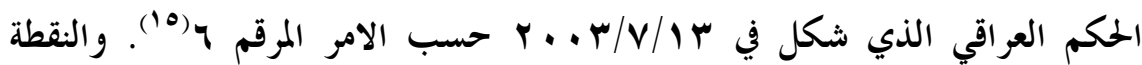

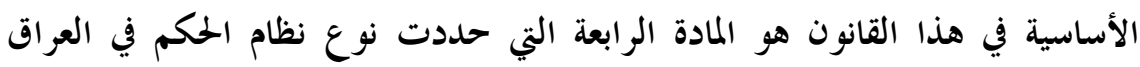
واستخدام مصطلح " تقاسم السلطات " فيه بين الحكومة الاتحادية والحكومات

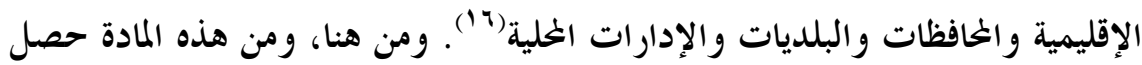

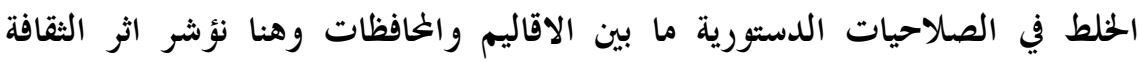
السياسية للحاكم المدني في العراق ومجلس الحكمم في اعتماد منطق الاستنساخ ونقل تجربة سياسية للعراق من دون النظر والاعتبار للشروط الاجتماعية - الثقافية ناهيك عن الشروط السياسية ـ والخلط هو ما بين قو اعد ومبادئ تتسم بها اللامركزية الادارية

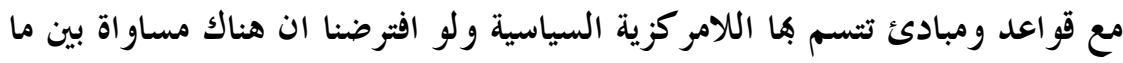
هو سياسي ولما هو اداري لما اقتضت الحاجة المعرفية والأكاديمية والقانونية للثفريق ما لمانس

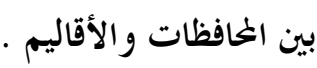

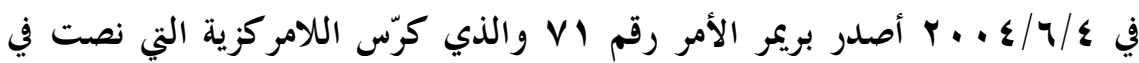

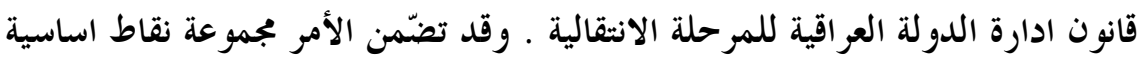

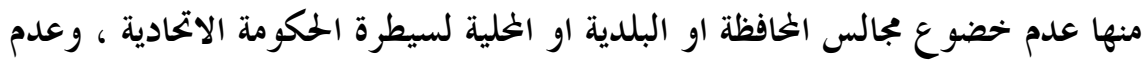
جواز إقالة الخافظ من الحكومة الاتحادية والحق للمحافظات بتشكيل اقليم فيما بينها (IV) وفي الواقع فان قانون ادارة الدولة العراقية للمرحلة الانتقالية قد نصت بعض مواده

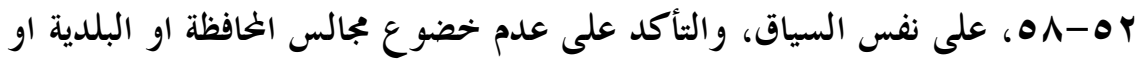
الخلية لسيطرة الحكومة الاتحادية(1) . وهنا يمكن لنا ان نتصّور ان محافظ لاحدى الخحافظات او مدير لاحدى نواحي تلك

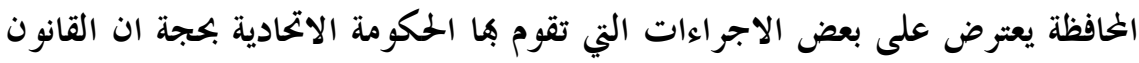

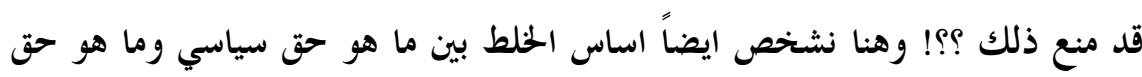

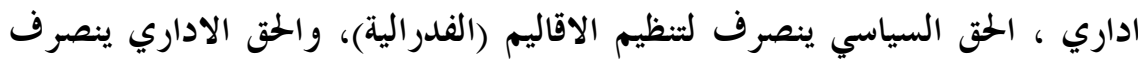


لتنظيم الخحافظات (لامركزية ادارية) ، المى جانب اعضاء الخافظات حق سياسي وهو

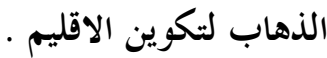
وعلى مستوى الثقافة السياسية للمصطلحات المستخدمة نتساءل كيف يمكن ان نطلق على قانون ما بقانون ادارة الدولة ونحن قد شهدنا اجر اءات سياسية لإفهاء وجود الدولة لهولة

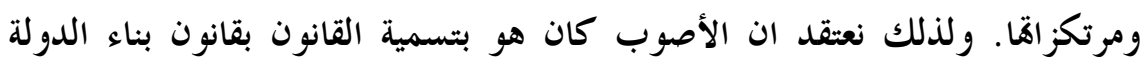

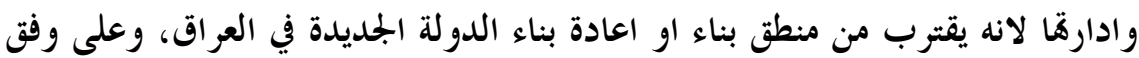
فلسفة سياسية جديدة. ونفس التساؤل يثار حول مصطلح ممارسة السلطة في الامر VI وكيفية السماح لممارسة سلطة لامركزية ادارية ولكن بصيغة سياسية، وكيف ونحن في بداية تجربة

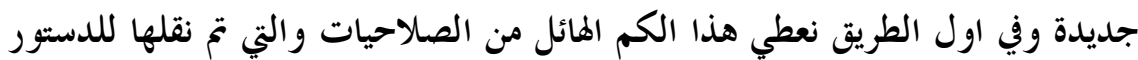

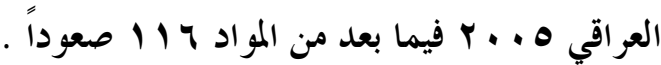

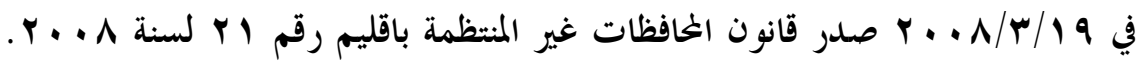

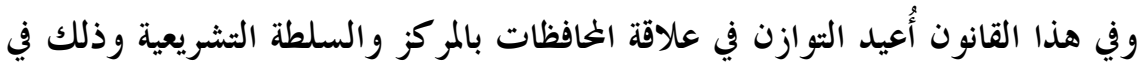

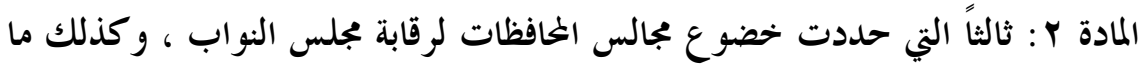

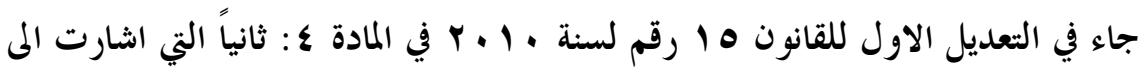
ان لجلس النواب ان يعترض على القرارات الصادرة من الجلس ، و كذلك ما جاء في

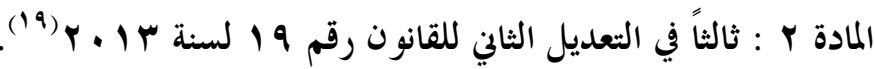
ومع ذلك فان هذه النصوص لم تمنع الصراع السياسي ما بين انماط عديدة للثقافة السياسية العر اقية للقوى السياسية والحزبية وطبيعة توجهاتما المى جانب طبيعة الثقافة السياسية لمن يتصدّى للمسئولية . وهنا نشخّص اراء وارادات متصارعة فالفريق الاول يريد مركز ضعيف واطراف قوية، والفريق الثاني يريد مركز قوي (مركزي وليس اتحادي) واطراف ضعيفة ، والفريق

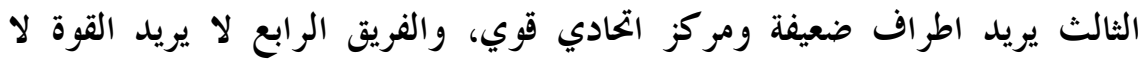
للمركز ولا للاطراف ، والفريق الخامس وهو الذي يستند المى ثقافة سياسية ناضجة 
فيذهب باتجاه تقوية المركز والاطراف باعتبار ان العلاقة بينهما هي تكاملية وليست تنازعية - تصارعية. هذا المى جانب تعارض أنماط الثقافة السياسية للنخب ما بين ثقافة سياسية حزبية مشوهّه وثقافة السلطة غير المقيدة من جهة، وثقافة سياسية ترتبط بفكرة الدولة والمؤسسات

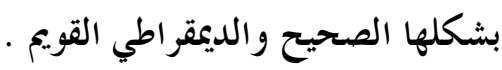

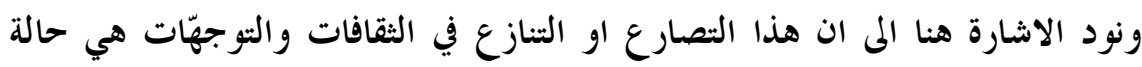

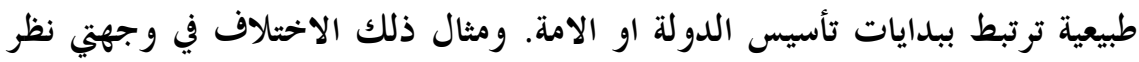
كل من توماس جفرسون والكسندر هاملتون في طبيعة العلاقة بين الحكومة الاتحادية والحكومة الخلية. فكان توماس جفرسون يكون يميل المى الاخذ باللامركزية في توزيع

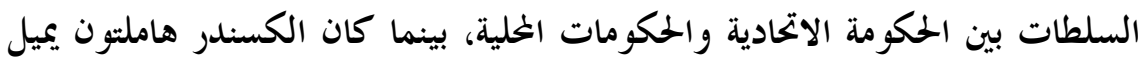

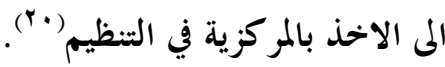
والمشكلة هنا هي حلول الفكرة المكوناتية في هذا الصراع وأصبح الصراع ليس بئ بين

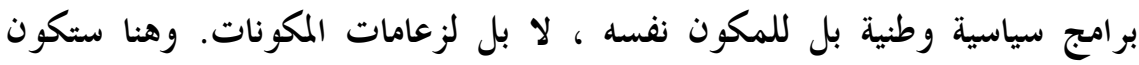
الثقافة السياسية الضيقة والفرعية هي السائدة، وليس تلك المستندة للهوية الوطنية.

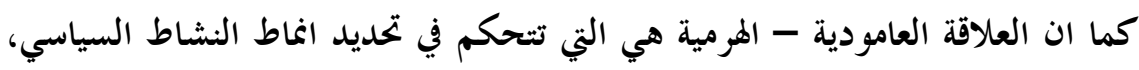
وليس العلاقة الافقية ـ وما تحتاجه اللامركزية هو ثقافة سياسية تشجع العلاقات الافقية

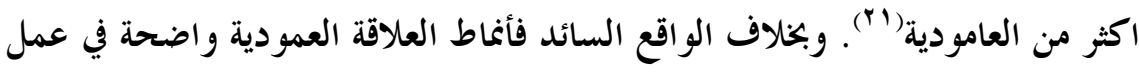

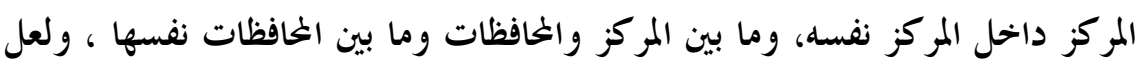

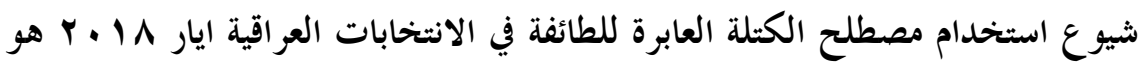
بمثابة اقرار بضعف العلاقات الافقية . وفي اطار العلاقة المثفاعلة ما بين ما هو عامودي وما هو أفقي، يمكن القول ان غياب النياب

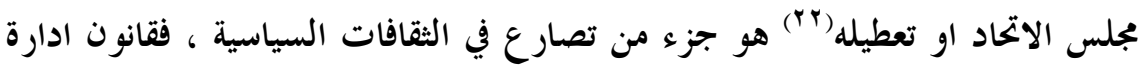

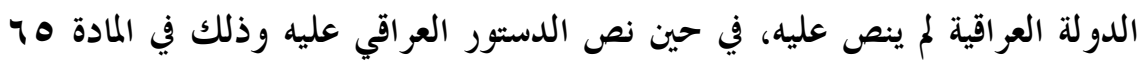
ولكن مع التأجيل والثرحيل ـ وجوهر التصارع يتمثل في اعتقاد طرف من ان التمثيل 
المكوناتي للمحافظة والاقليم يكفي، وطرف آخر يعتقد في ان وجود الجلس يمكن ان

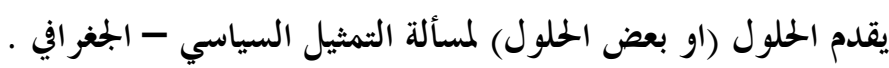

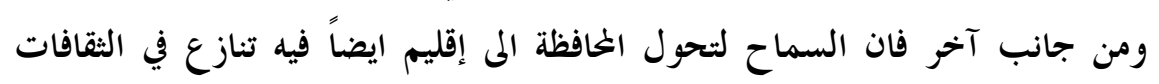

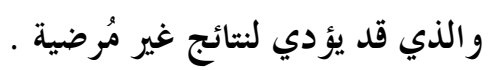

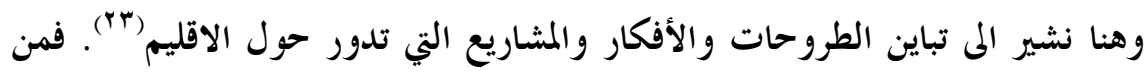

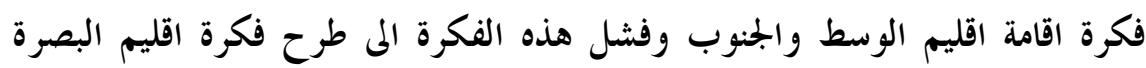

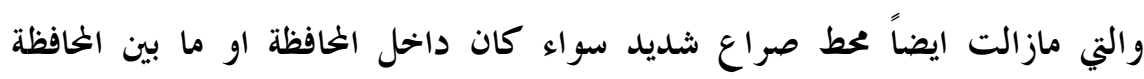

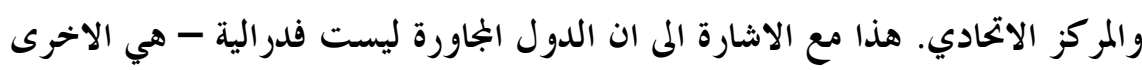

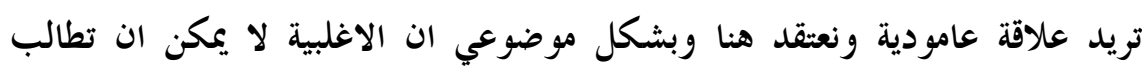

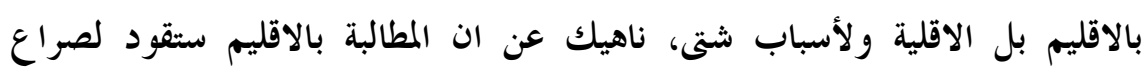

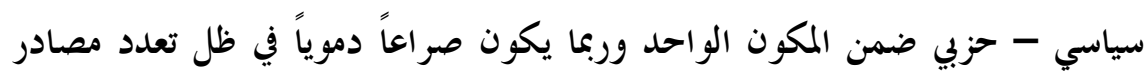
تواجد السلاح خارج نطاق سيطرة الدولة . .

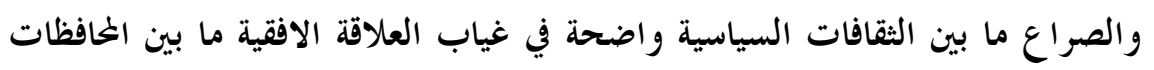

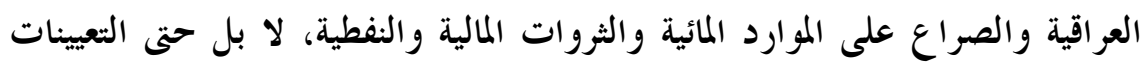

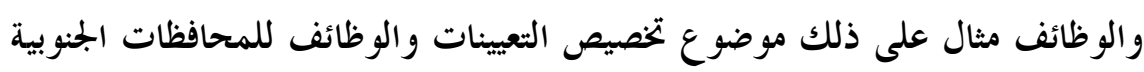

$$
\text { بعد احداث البصرة الاخيرة (צ'). }
$$

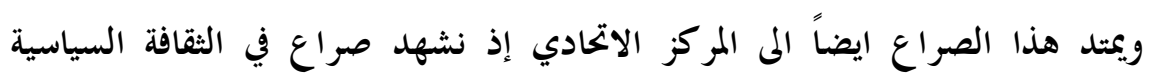
لاعضاء مجلس محافظة بغداد ومجلس مدينة بغداد ، او في عدم وضوح الرئ الرؤية في التعامل

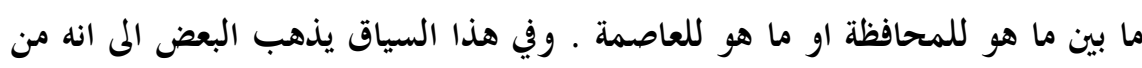

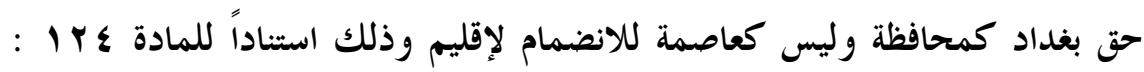

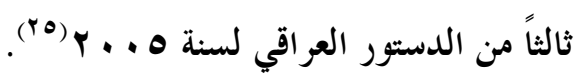

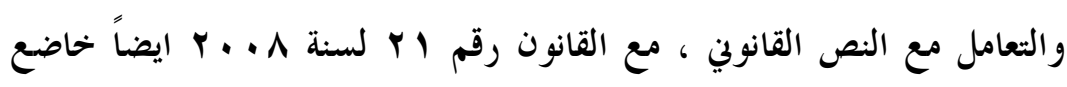

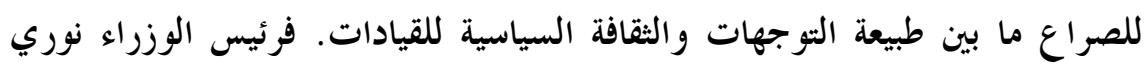

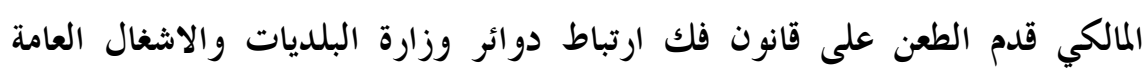

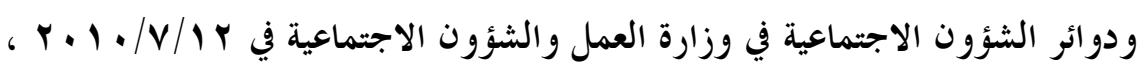


كما قدم المالكي في • //كانون الاول / با +ب طعن للمحكمة الاتحادية لإيقاف

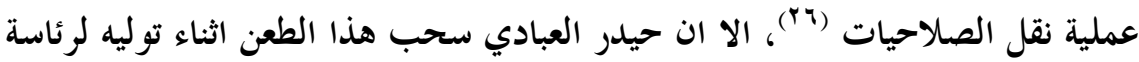

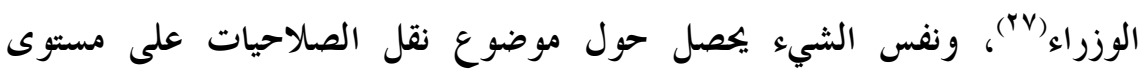

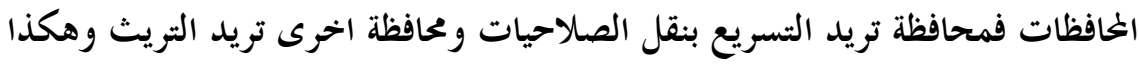

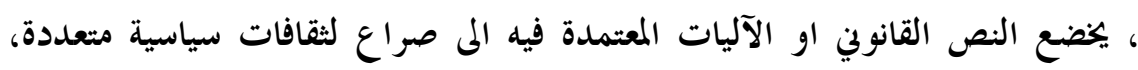

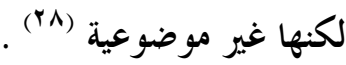
والاختلاف في التوجّهات والمعارف حول الثقافة السياسية للمحافظين تتفاوت ايضاً ،

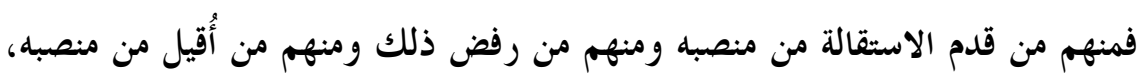

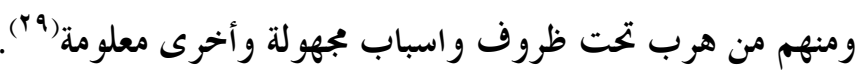
ما نريد ان نقوله هنا هو ان صراع الثقافات السياسية ما بين المسؤولين على مستوى معرده

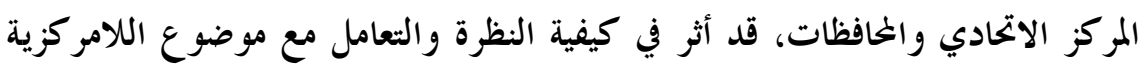
بكونه حق اداري ام سياسي .

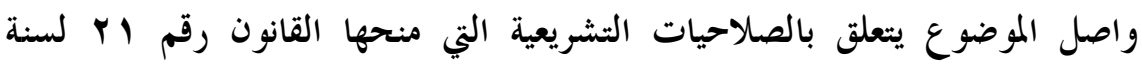

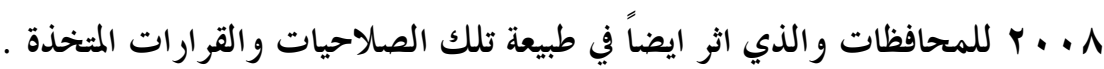

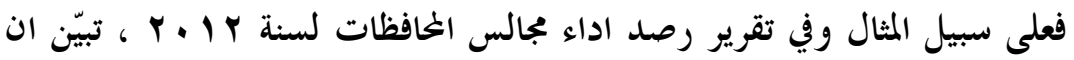
محافظة بغداد قدمت ع مقترحات قوانين وهي لا تمتلك الصفة الخلية فتشريع قانون

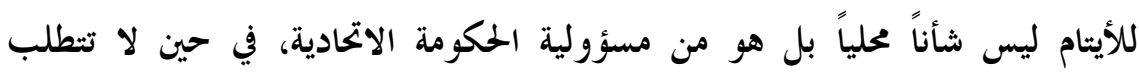

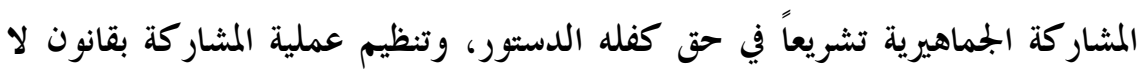
تختص بمحافظة من دون اخرى. وقد يبدو وضع قانون لتحديد الرسوم على الحخدمات

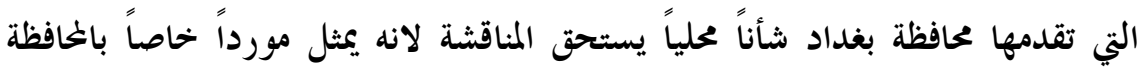

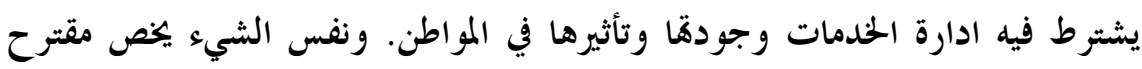
القانون الذي قدمه مجلس محافظة بابل حول العنف الأسرى فهو من اختصاص مجلس

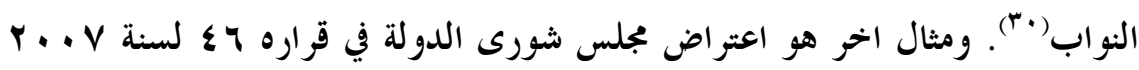

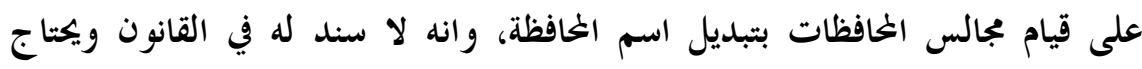


لتدخل تشريعي(") . . وهذا الصراع يقودنا المى المسألة الثانية التي تتعلق بدرجة

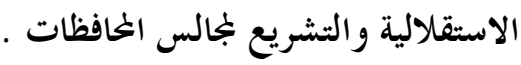
المسألة الثانية : درجة الاستقلالية والتشريع

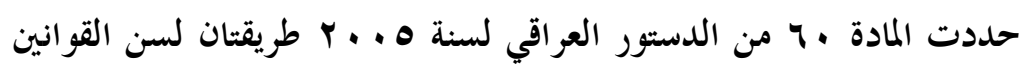

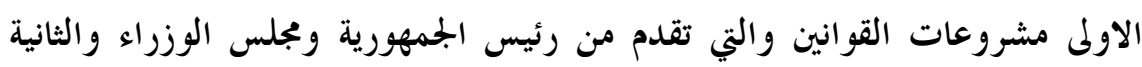

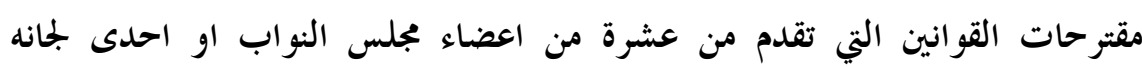
(r) المختصة المعتوحات اما المادة الج : اولاً من الدستور فقد نصت على ان مجلس النواب يخنص بتشريع

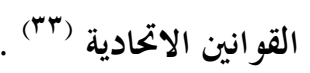
وقد نظّم النظام الداخلي لجلس النواب العراقي في الفصل الرابع عشر اقتراحات

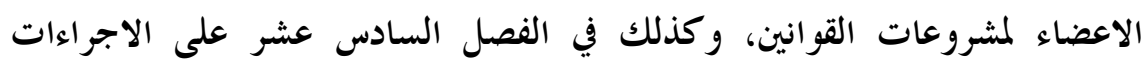

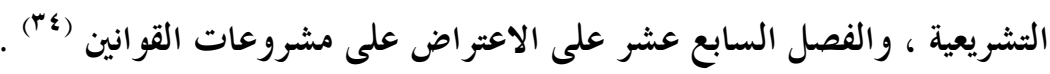

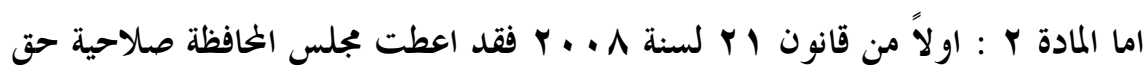

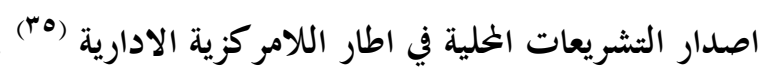

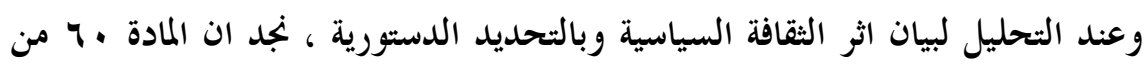

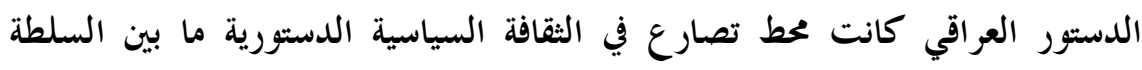

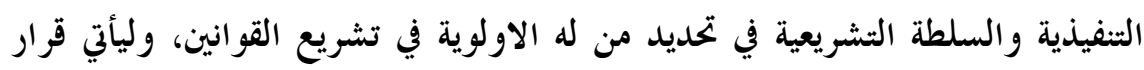

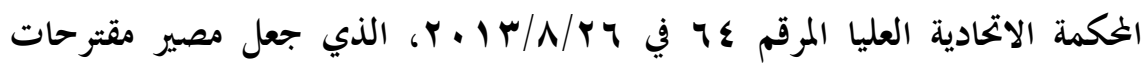

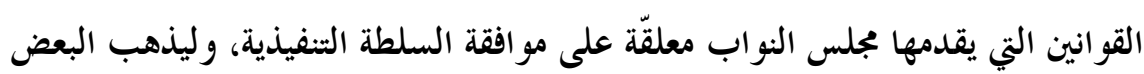

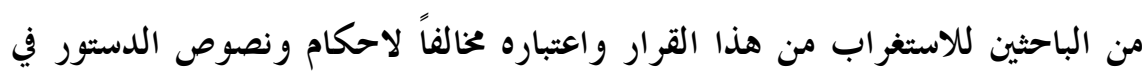

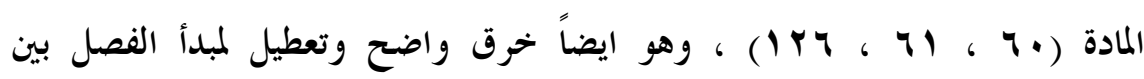

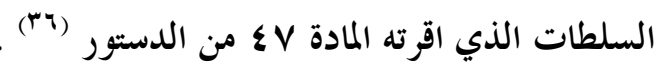


والصراع ما بين الثقافات يعود من جديد ولتراجع الخكمة الاتحادية عن قرارها السابق

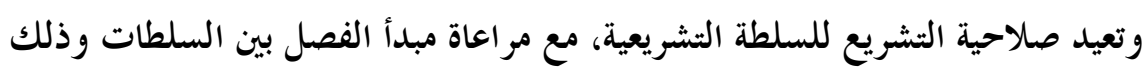

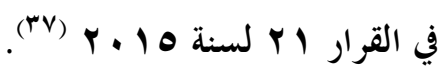

وفي الواقع ان سلب الحق في ظل حكومة وارجاع الحقى في ظل حكومة اخرى، من شأنه

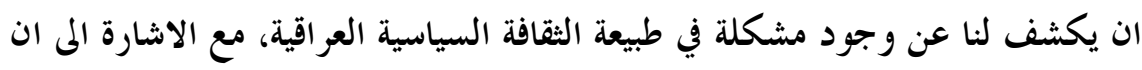

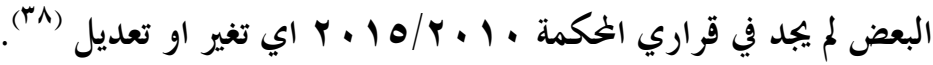

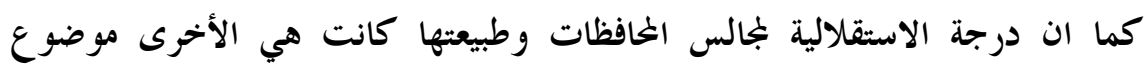
تصارع في الثقافة السياسية فهناك من ترسخت لديه ثقافة الحوف من المركز وليذهب المى تأييد اعطاء صلاحيات واسعة لجالس الخافظات، مع عدم اغفال فكرة او امكانية

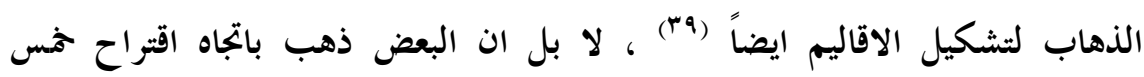

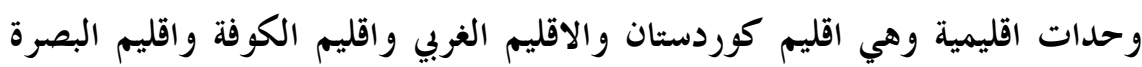

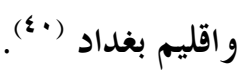

واذا كان هناك من يُعيب على مجلس النواب العر اقي في طبيعة التشريعات القانونية من

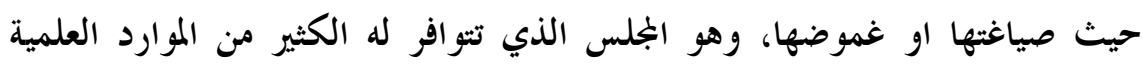

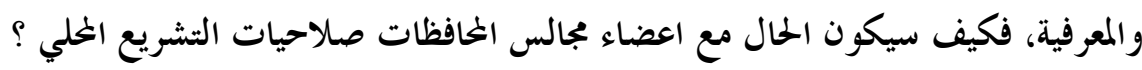

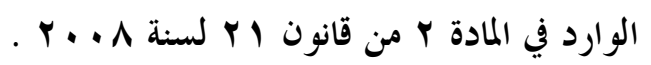

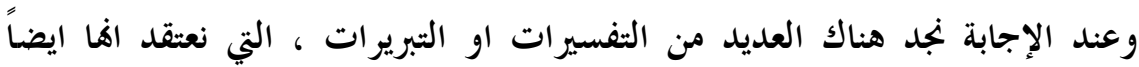
تختلف باختلاف طبيعة الثقافة السياسية لمن تبنى ذلك الثفسير والتبرير. فهناك من فسر التشريعات الخلية على اها تلك التي يصدرها البجلس والتي تتعلق بادارة

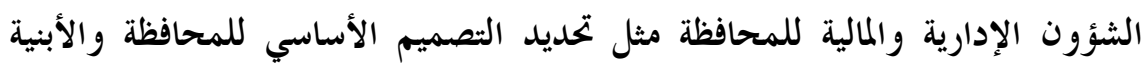
وفرز الأراضي السكنية ومنح رخص المهن المختلفة، ووضع الاسماء التجارية (1).

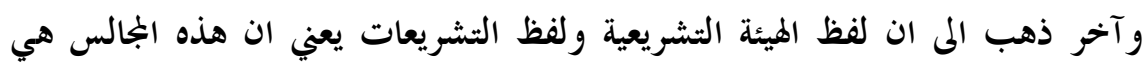

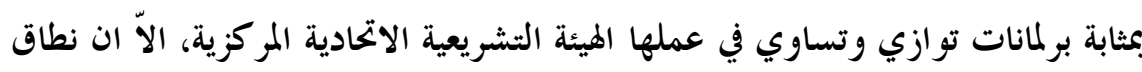

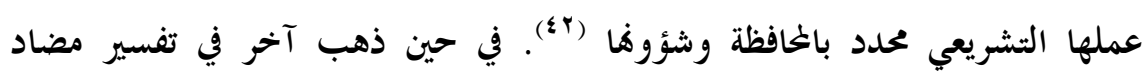
وذلك حين قال "ان هناك قيدان حصريان يمنعان اصدار التشريعات الخلية لعدم 
الصلاحية الدستورية لان المادة ب r I / ثانياً لا تمنح الخافظات اكثر من صلاحيات مالية

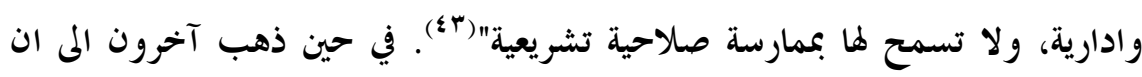

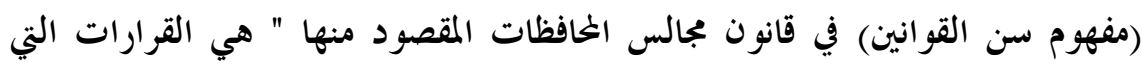

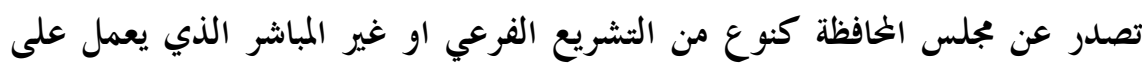

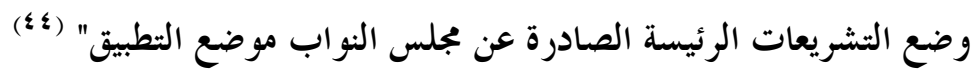

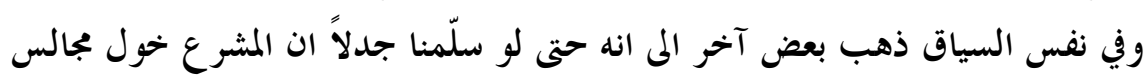

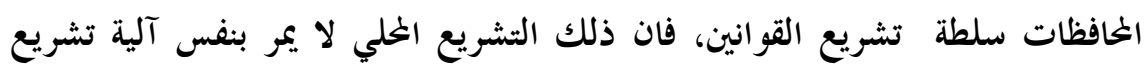

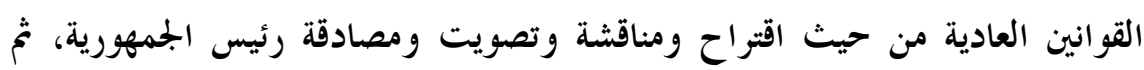

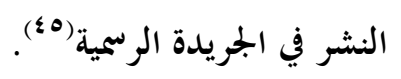

ومن جانب آخر نتساءل عن طبيعة الثقافة السياسية لعضو مجلس محافظة او رئيس

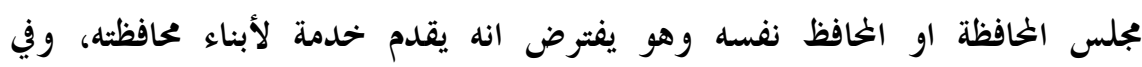

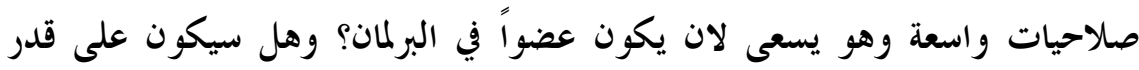

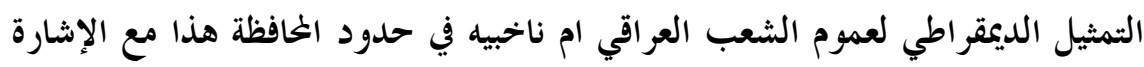

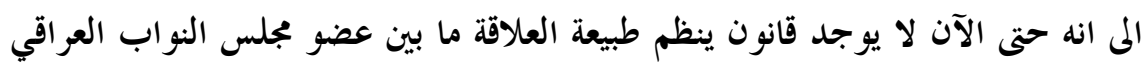

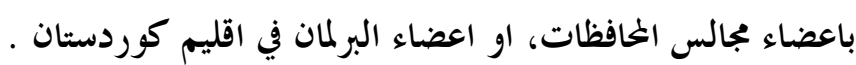

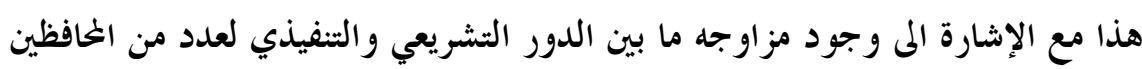

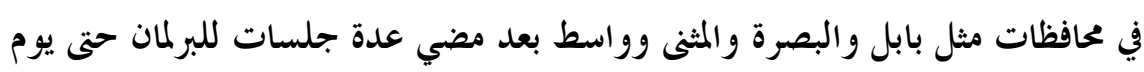
$r \cdot 11 / 1 \cdot / 1 \varepsilon$ المسألة الثالثة : ذكورية مجالس الخافظات

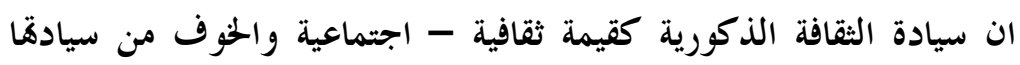

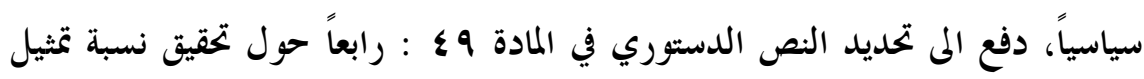

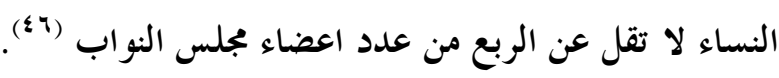

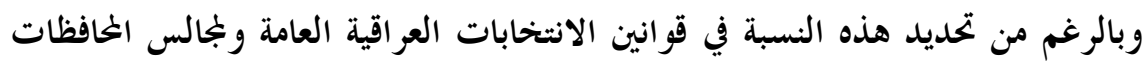

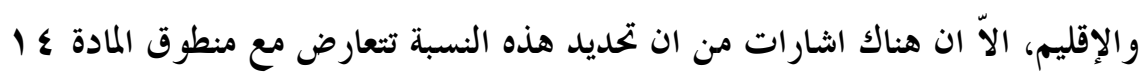


من الدستور العراقي التي تتحدث عن " العراقيون متساوون "، و كذلك مع منطوق

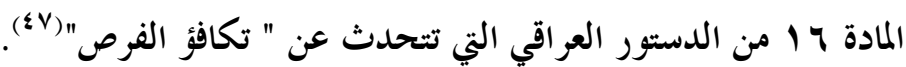

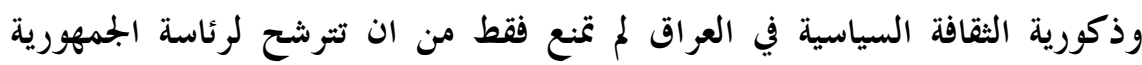

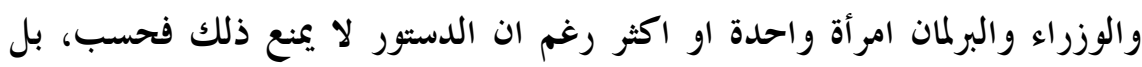

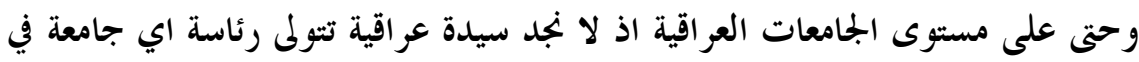
العراق لا من الحكومة ولا من الأهلية . ونفس الشيء نجده على مستوى مجالس الخافظات اذ لم نجد لا رئيس مجلس محافظة ولا محافظ من السيدات . وقطعاً ان المرأة العر اقية تملك العديد من المؤهلات والكفاءات ونخص منهن المستّقلات وليس المتحزبّات، او تلك التي تعتمد على الخسو بية والمنسو بية في تولي المناصب العلمية ولمدية او الادارية او السياسية .

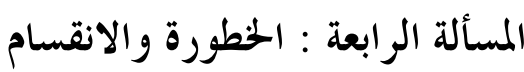
يعتقد العديد من الباحثين في الثأن السياسي العراقي من ان النخب السياسية العراقية

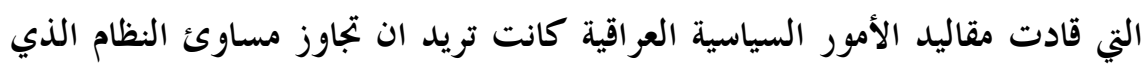

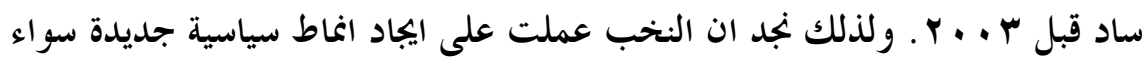

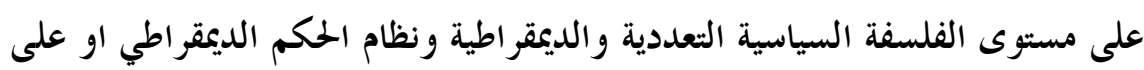

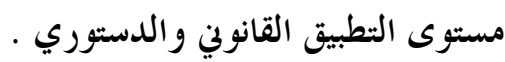
وضمن هذا السياق وجد البعض من ان الحخوف الذي بات يلاحق المكونات الأخرى

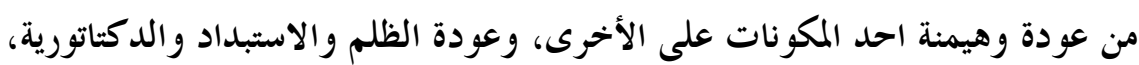

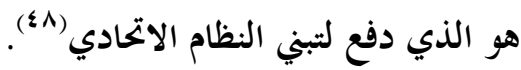
ويؤكد هذا الرأي احد السياسيين العراقيين وهو يتحدث عن الدين عملية كتابة الدستور

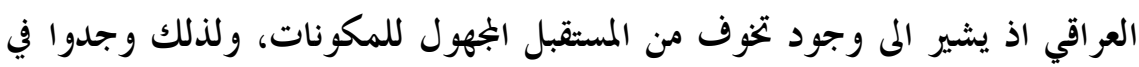

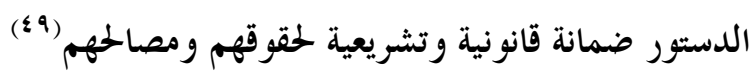




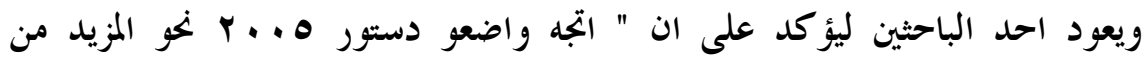
الصلاحيات باتجاه الاقاليم والخافظات على حساب المركز تحت تأثير رد رد الفعل على مساوئ المركزية الشديدة للنظام السابق، على حساب التوازن بين وحدة العراق من

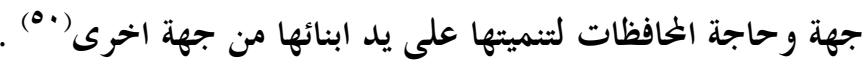

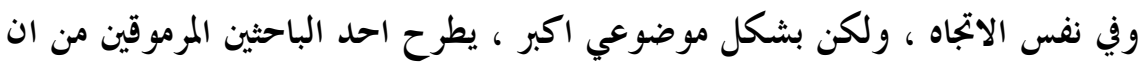

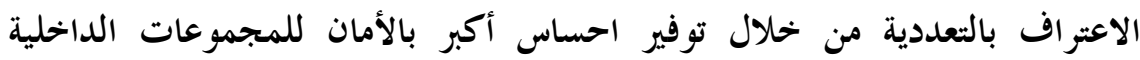
المختلفة، قد أدى في معظم الأحيان الى التخفيف من حدّة التوتر (1).

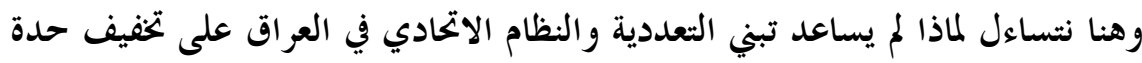

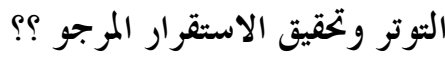

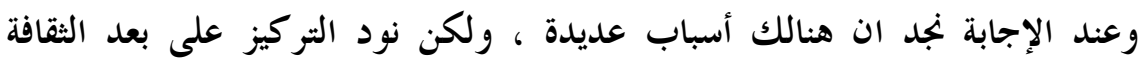

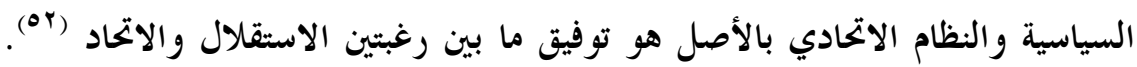

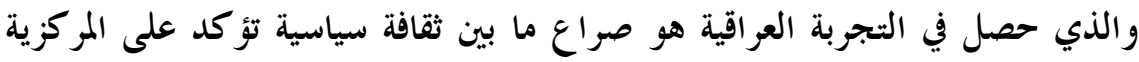

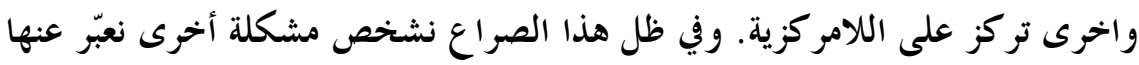
بمجموعة تساؤلات منها:

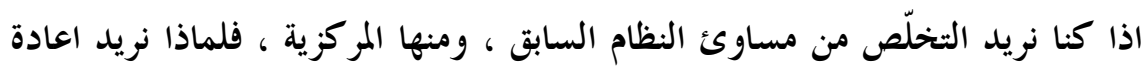
تجربة المركزية، وان كانت في ظل نمط جديد من الفلسفة السياسية الديمقراطية ؟ ولماذا تخوف من اللامركزية (السياسية والإدارية) او السياسية فقط منها (الفدرالية) ؟

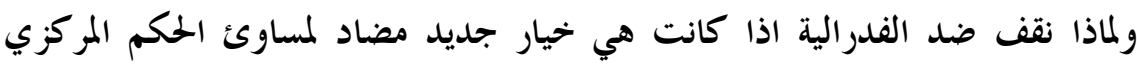

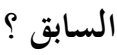
ولماذا لم تتوحّد الثقافة السياسية العراقية وهي تعّد العّدة لاحتلالها مو اقعها ومناصبها لقيادة العراق منذ ان كانت هي في المعارضة ؟ ام انه الاختلاف بالثقافات السياسية الفرعية الفئوية المكوناتية - الطائفية - العرقية

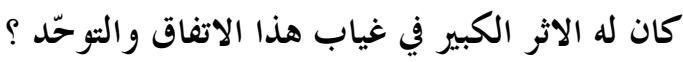
وضمن هذا السياق يمكن القول ان هناك التجاهات ورؤى ، وهي انعكاس لثقافاتما السياسية ، تعتقد بان تجربة اللامركزية تعني الضعف والوهن سواء كانت بالثق 
الاداري ام السياسي ولذلك شهد العراق وفي أوساطه السياسية - الاجتماعية -

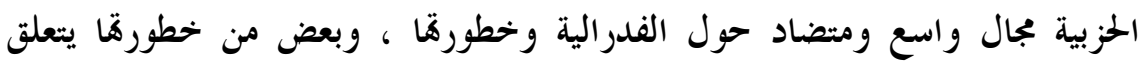

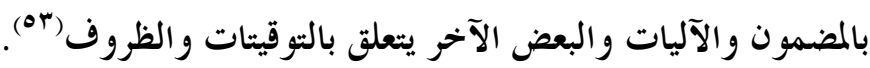

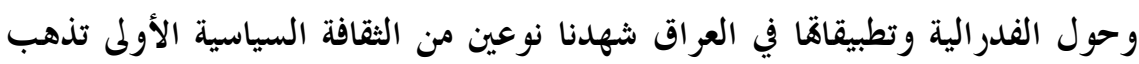

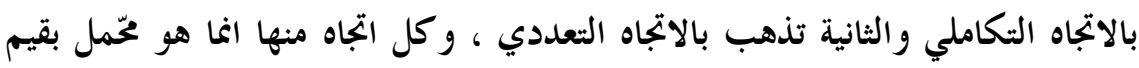
ومشاعر ومعارف ومعتقدات محددة .

واذا كان الحخف من الفدرالية باعتبارها تقود للضعف والوهن في جسد الدولة، فلماذا

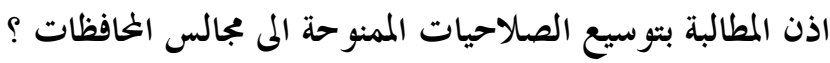
ولماذا ساوى المثّرع ما بين صلاحيات الإقليم والخافظة في الدستور العراقي سواء باستخدام مصطلح الحكومة لكليهما، او من حيث صلاحية التشريع وسن القوانين ؟

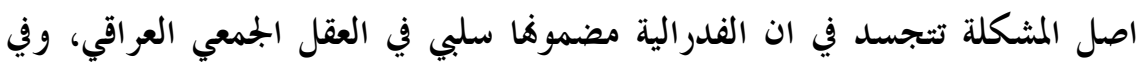

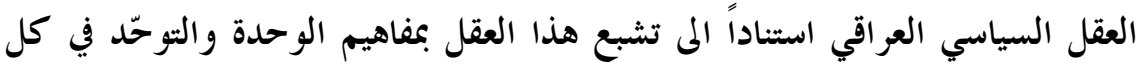

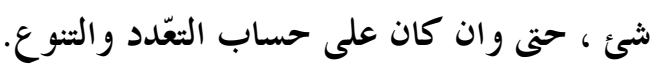
وهنا نقول ان واحدة من أسباب انهيار النظام السابق، انما هو انكار التنوع والتعدد وفرض الوحدة والتوحد بأساليب اكراهية وليس اقناعية . كما ويمكن القول ان اي نخبة سياسية حين تنادي بتوسيع الصلاحيات لخجالس الخافظات سوف تكون في مأمن من الابتعاد سواء من حيث الدلالة اللغوية المختلفة (لخافظة)

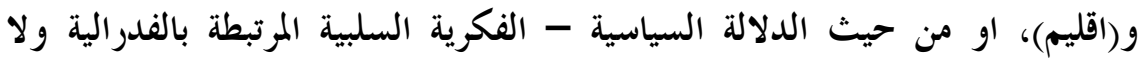
ترتبط بالخحافظات . لا بل ان الحياة السياسية العراقية شهدت ان نخباً عراقية ايدت او عارضت الفدرالية والإقليم لاسباب شتى بعضها يرتبط بالجانب العقائدي - الفكري، وبعضها الآخر

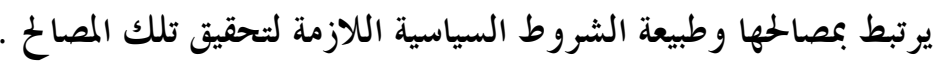

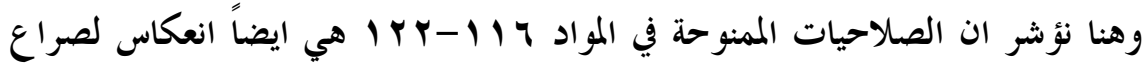
حزبي - سياسي مشفوع بقيم ثقافة سياسية تقليدية او خاضعة، وليست تشار كية حتى 
داخل المكون الواحد او هي صراع مكوناتي على اسس ادارة السلطة ومواردها المختلفة .

والقناعات والمعارف والاتجاهات ايضاً تتبّدل ، بفعل الشروط والظروف السياسية ،

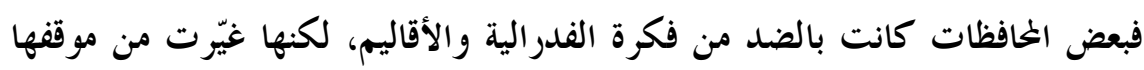
هذا ولتؤيد إقامة الإقليم ليس لخافظة واحدة، بل لعموم المكون في محافظات عدئ باتهدة

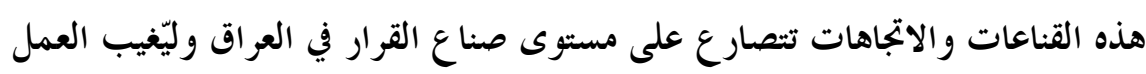

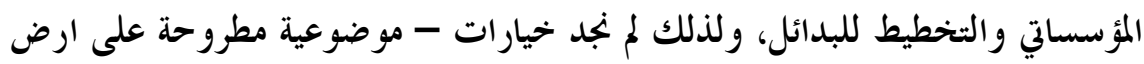

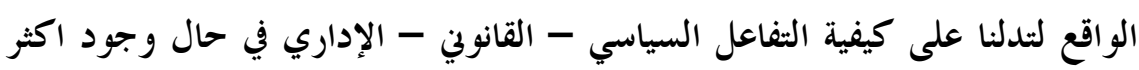

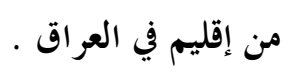
وحتى في ظل ما هو سائد في اطار عمل مجالس الخافظات نجد التصارع السياسي ، وهو

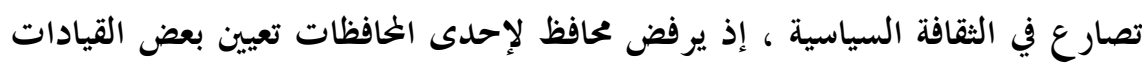

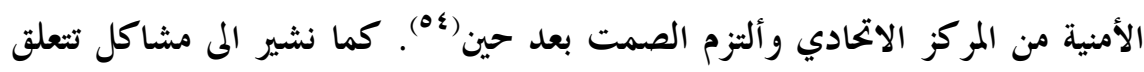

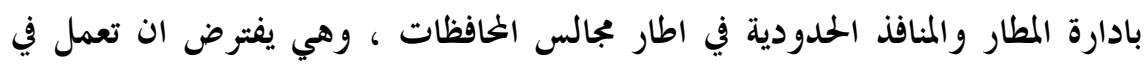
اطار اللامركزية الادارية وليس السياسية ، وهذا يستدعي من المركز الاتحادي التعامل

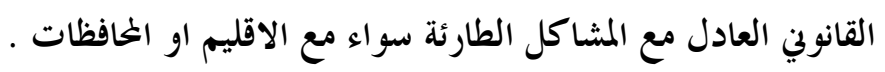

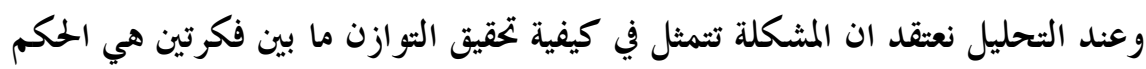
الذاتي والحكم المشترك ، التوازن ما بين ان يكون لدى نسئد المبلد كبيرة من السكان شعور بالهوية مع البلد ككل، بالإضافة المى مجتمعات محلية على المستوى الإقليمي تتسم

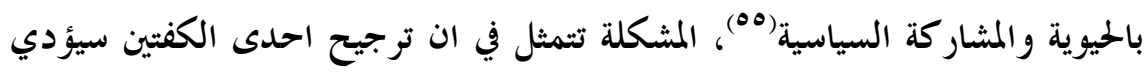

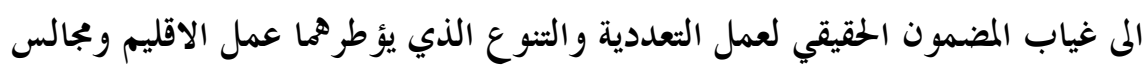
الخافظات .

المسألة الخامسة : التزاحم ما بين مفاهيم الرقابة والتفويض والتشاور والتنسيق والتعاون

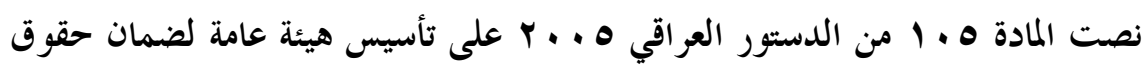

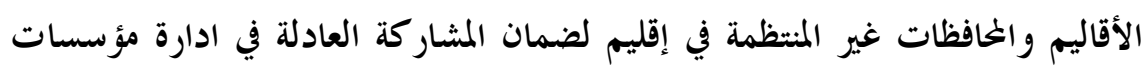

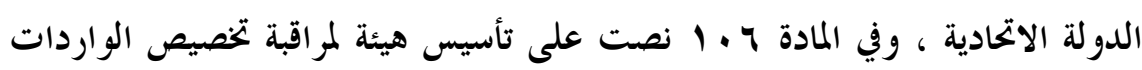


الاتحادية وللتحقق من عدالة توزيع المنح والمساعدات والاستخدام الأمثل للموارد المالية

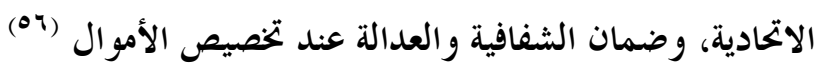

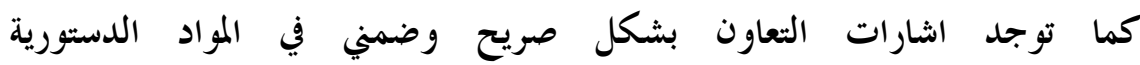
(OV) 11 \& (1) $111 \mathrm{r}$

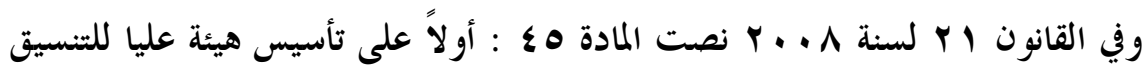
بين الخافظات (ه1)

اما عن تفويض الصلاحيات فقد نصت عليه المادة سبا من الدستور العراقي والتي

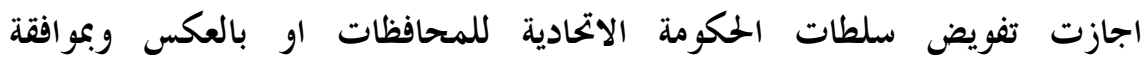

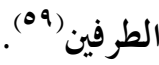

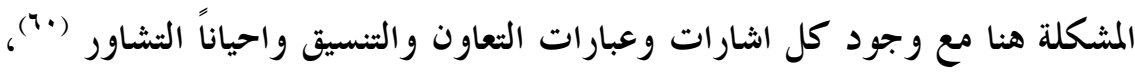

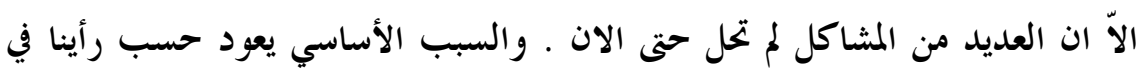

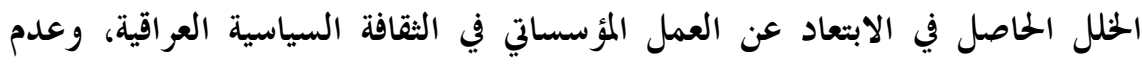

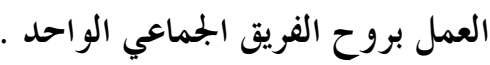

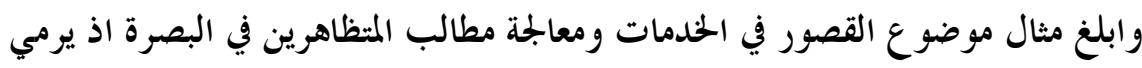

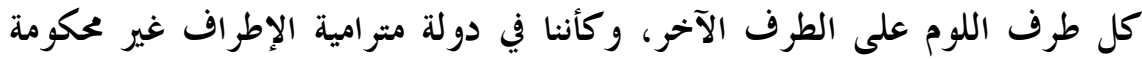

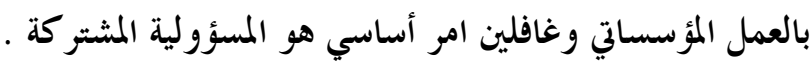

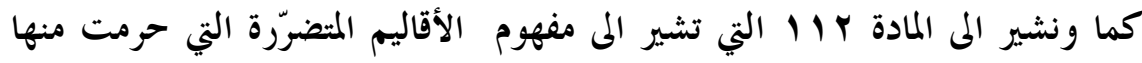

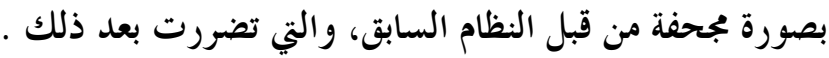

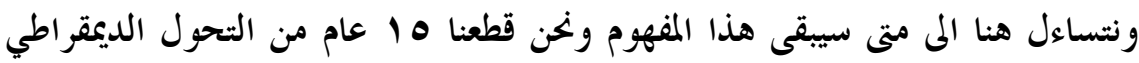
وانفاق مئات المليارات من الدولارات .

المسألة السادسة : المفاضلة ما بين الانتخاب والتعيين او تعديل النظام الانتخابي

نصت المادة V : الفقرة ب من الدستور العراقي لسنة • 19V على تقسيم

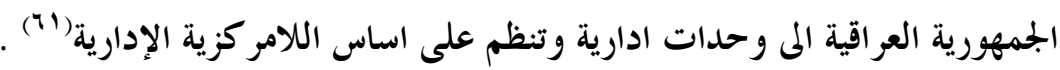


وعند تحليل هذه المادة في ضوء الثقافة السياسية نجد انه من الطبيعي غياب اللامر كزية

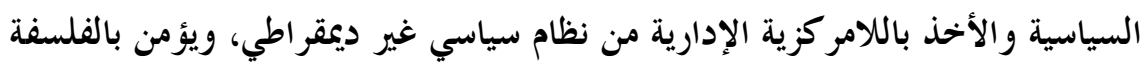

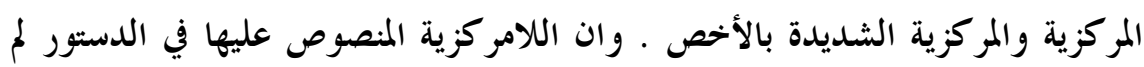
يكن تطبيقها بالمعنى الحقيقي لمضمون وروح اللامركزية الادارية، واعتماد التعيين

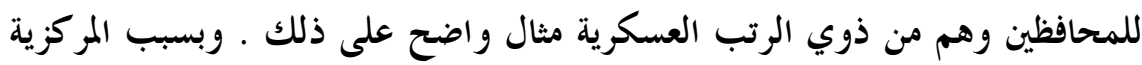

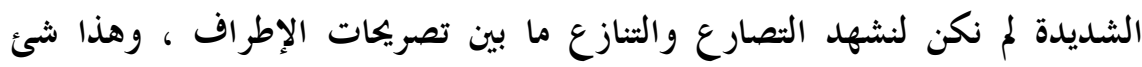

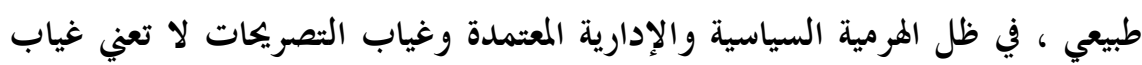

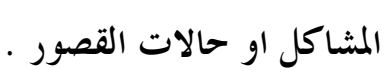

وهنا نتساءل لماذا اذن تظهر المشاكل بحدّة في ظل النظام السياسي الديمقراطي ؟؟ لهُ

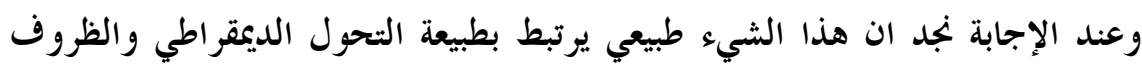

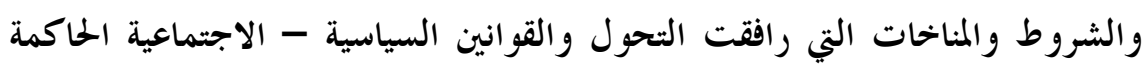

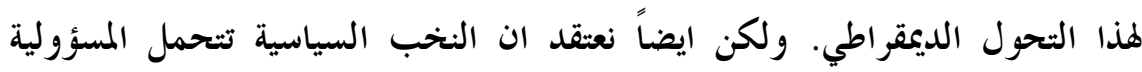

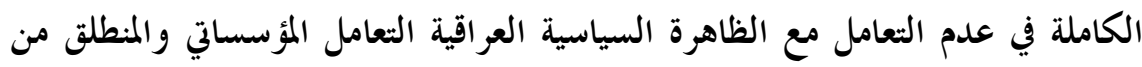

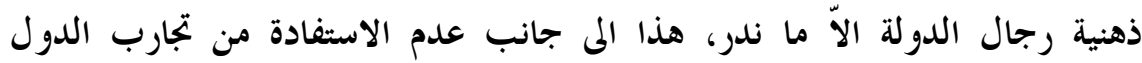

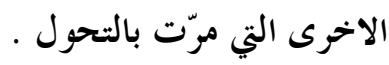
وعلى سبيل المثال فان ثقافة الاباء المؤسسون ورجال الدولة ذا رؤية غائبة في المركز

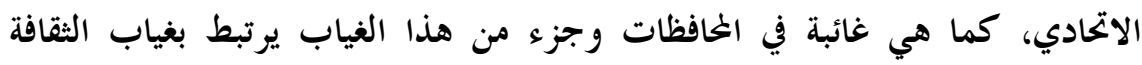

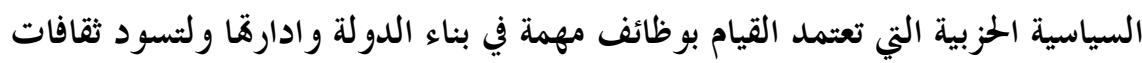

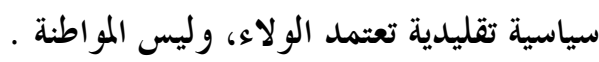

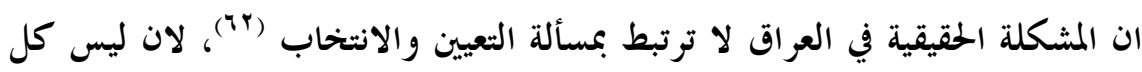

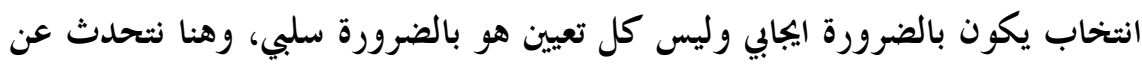

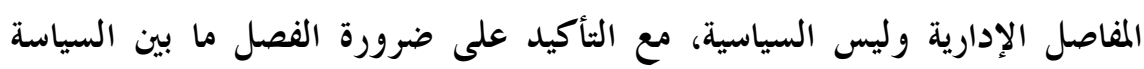

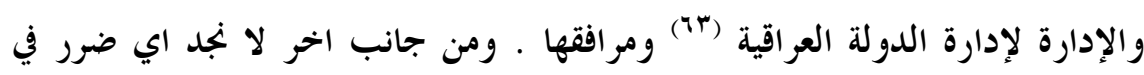

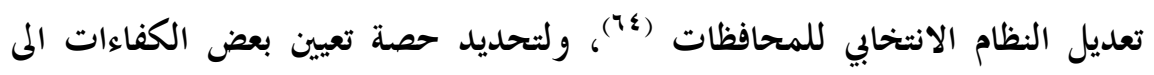


جانب مبدأ الانتخاب لانه من الممكن ان يخدم تلك الخحافظات، ولكن بشرط ان يكون

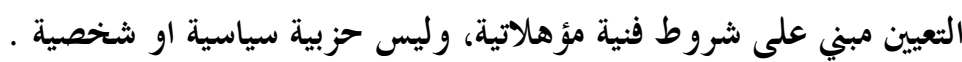
المسألة السابعة : المضمون والثكل تئي ان جوهر اللامركزية هو نقل وتفويض سلطة التخطيط واتخاذ القرار وادارة

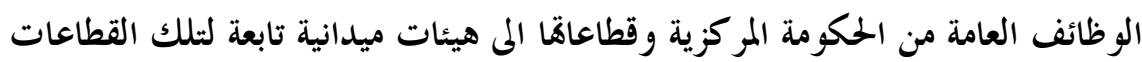

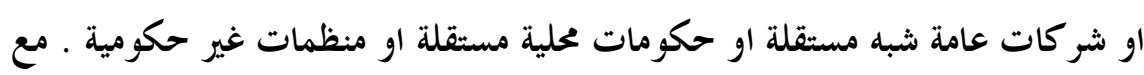

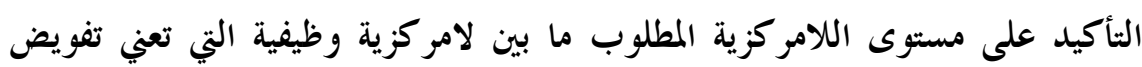
السلطة للقيام بمهام محددة المى منظمات متخصصة في اداء تلك الوظيفة، ولامركزية

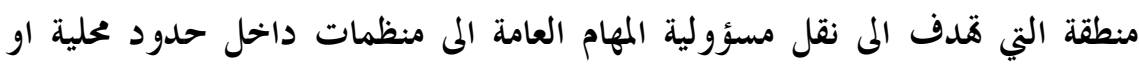
جغر افية او سياسية محددة بشكل جيد (10).

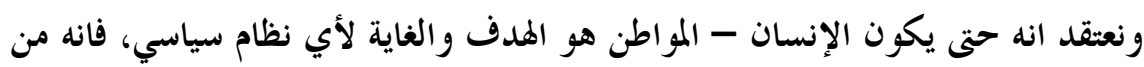
الضروري ان يكون هدف اي اجراء لاي لامركزية هو خدمة المواطن وتوفير سبل

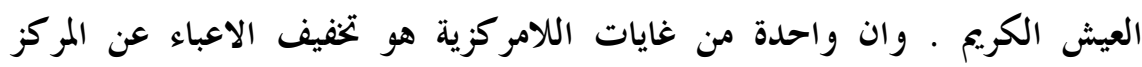

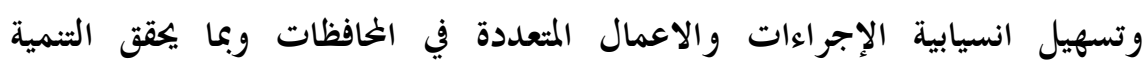

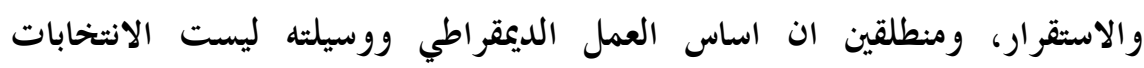

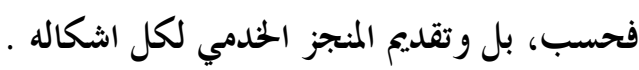
وهنا يرد الم الذهن تساؤلات المواطن العراقي البسيط ، التي تعبر عن مشاعر وآراء

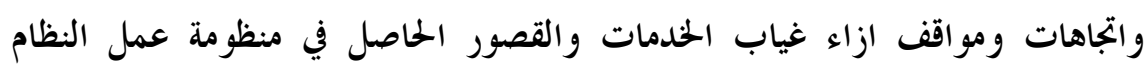

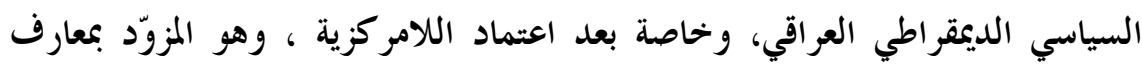

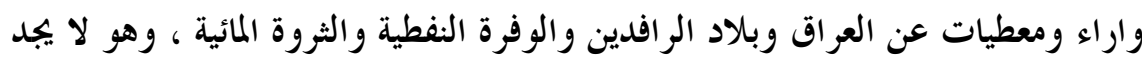

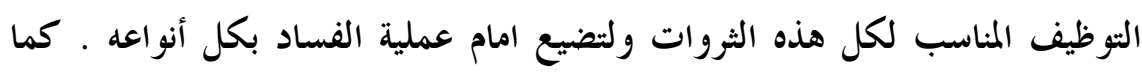

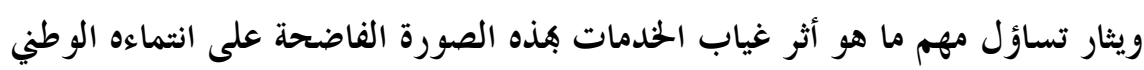
وسلو كيات المواطنة وطبيعة انتماءاته لمؤسسات الدولة ملئ العر اقية ؟ 
ويتساءل المواطن هل ان الحلل في المركز الاتحادي ؟ المشمول بالتصارع على المناصب

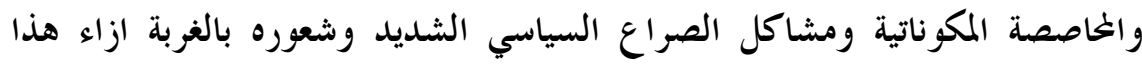
المركز ام ان الخلل في الاطر اف والخافظات، وتكون المشكلة اكبر وأعمق. ومن جانب آخر فان منطوق تخفيف الأعباء عن المركز وقيام الخحافظات بمسؤولياتا تحول في ذهن المواطن ، المى صراع سياسي ما بين المركز والخافظات والتصريحات

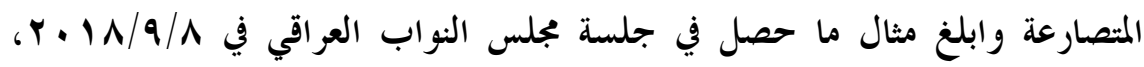
والتضارب في التصريحات ما بين محافظ البصرة أسعد العيدالي ورئيس مجلس الوزئ فئس الوراء

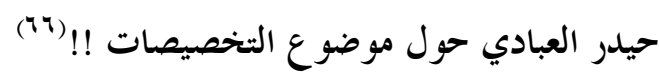
وما هو الأثر السلبي الذي يتركه مثل هكذا تصارعات على على اداء اللامركزية الادارية،

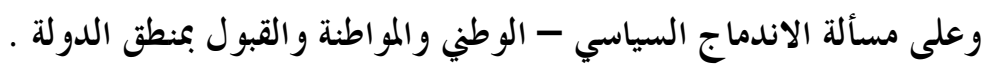

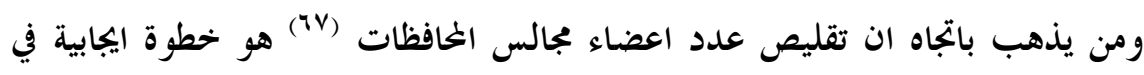
تقليص الهدر بالنفقات ، نقول هذا صحيح ولكنه لا يمس جوهر المشكلة التي تعاني منها

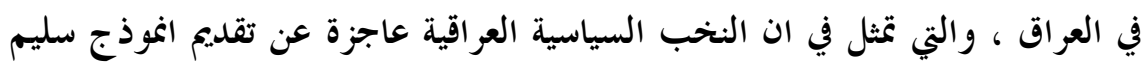
وموضوعي لتطبيق اللامركزية الإدارية والسبب الرئيس وراء ذلك هو عدم امتلاك

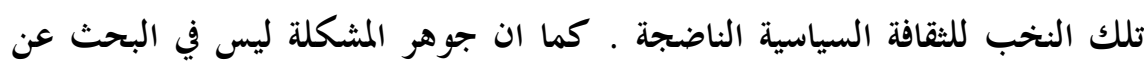

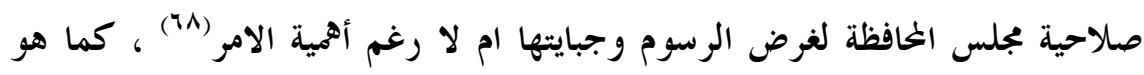
ليس في البحث عن مسؤولية التأخير في صرف مبالغ البترو دولار المتأخرة من المركز سواء كان بقصد ام غير قصد ، بل ان جوهر المشكلة هو في كيفية ايجاد الادارة

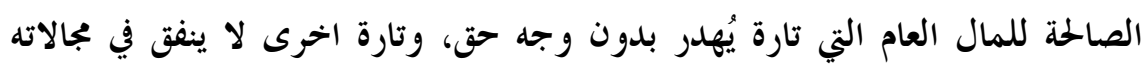
الصحيحة بحجة الخوف من المسئولية .

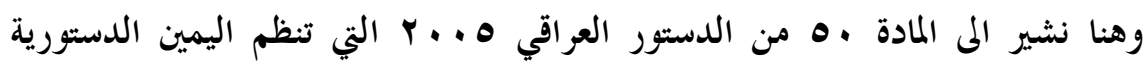

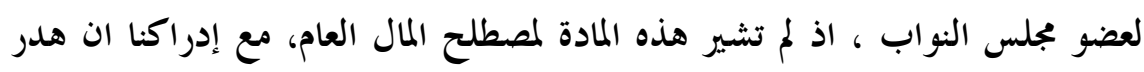

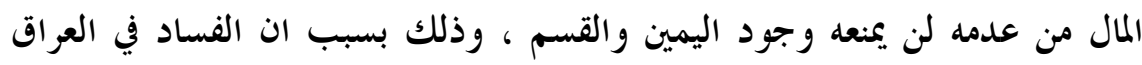
اصبح قيمة وثقافة سياسية سائدة مع وجود الخاصصة السياسية والتصارعات السياسية والتي راح ضحيتها المواطن العر اقي والمال العام . 
ولذلك نعتقد ان المعالجة الصحيحة لمشاكل الفساد والخاصصة في العراق لا تحل بثقافة

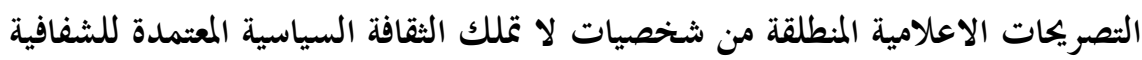

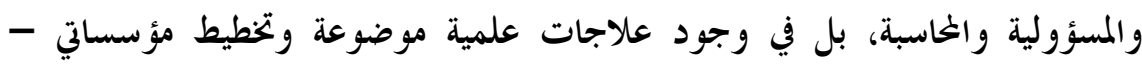

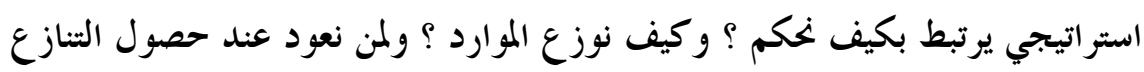

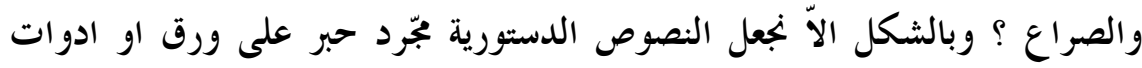

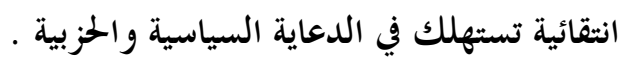
المسألة الثامنة : الثقافة السياسية - اسباب الغياب والترابه مما لاشك فيه ان الثقافة السياسية واكتساها يعتمد على عامل التنشئة والتراكم في الحبرات التي تأتي بمرور الوقت. وان التلازم ما بين المؤسسات وسلوكيات المسؤولين

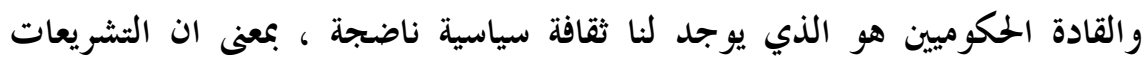

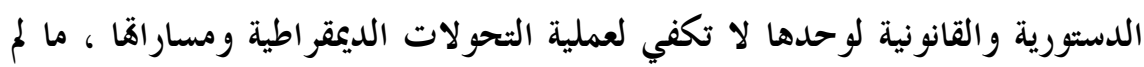

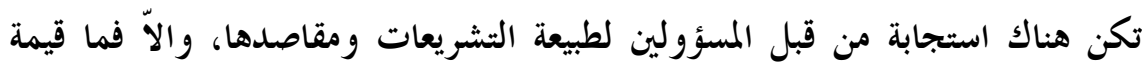
النص الدستوري وهو لا يوضع موضع التطبيق .

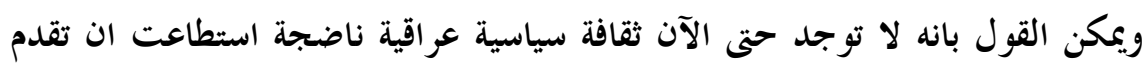

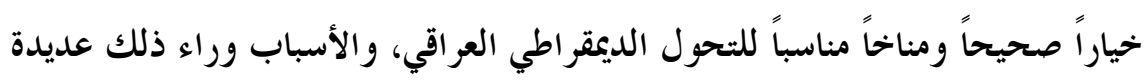
يمكن حصر بعض منها فيما يلي :

1. ان النخب السياسية العراقية لم تعمل على تعزيز ما تملكه من أوليات الثقافة

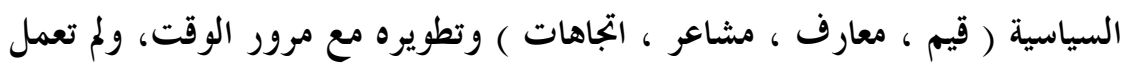
في حدود مجالات المواطنة والثقافة المدنية Civic Culture ، و انحصرت في مجالات

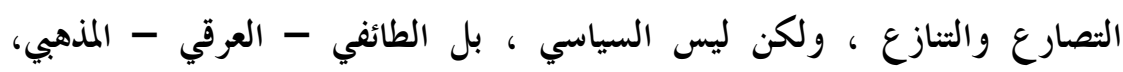

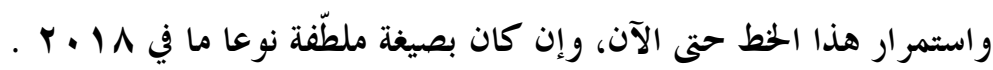
r. . الانشغال بالجانب الرسيمي للعمل الديمقراطي وإهمال المضمون الاجتماعي - الثقافي التي هي الحامل الحقيقي للتحول الديمقاطي ولذلك هناك فجوة واسعة ما بين 
القواعد الجُتمعية التي تعاني من العديد من المشاكل الجوهرية، وشرائح ترتبط بالقمة

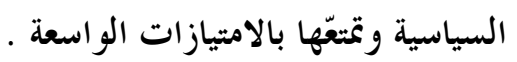

ان هذا التباين الطبيعي - الاجتماعي - السياسي أصبح من سمات العبات العملية السياسية في

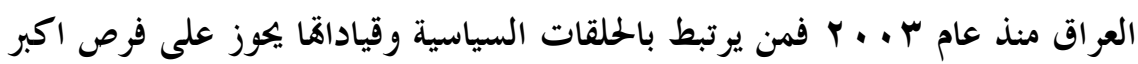

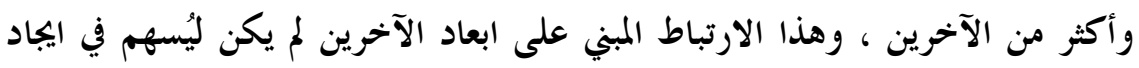

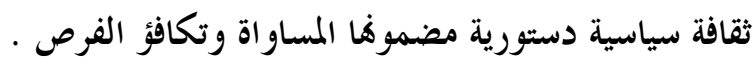
r. اعتماد النخب السياسية على التعريف الملتوي للسياسة ، فالأصل في السياسة اها

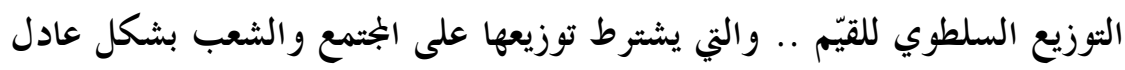

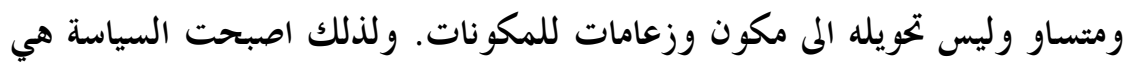
التوزيع الحزبوي - المكوناتي للغنائم، مع الاخذ بنظر الحسبان الفجوة الحقيقية بين

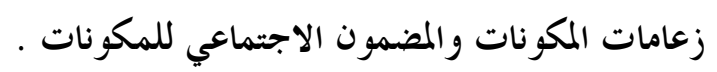

ع. الاعتماد على الولاءات الثانوية وليست المتعمدة على المواطنة والكفاءة، وهذا من

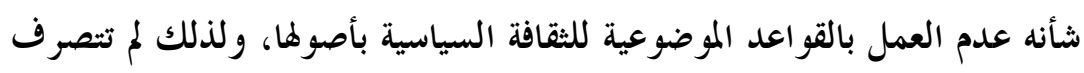

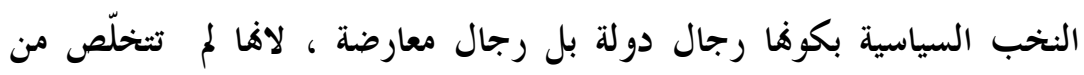

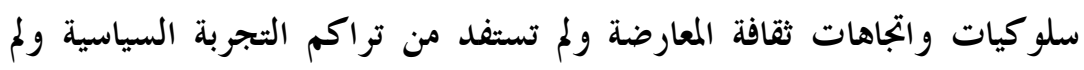
تتعلم من اصحاب الكفاءات، وعلاقات النخب السياسية مع الكفاءات بكل

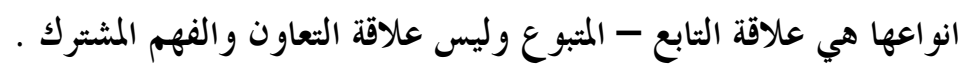
هـ قصور الظاهرة الحزبية من انتاج قيادات حزبية جديدة تفكر برؤية الدولة وبقاء

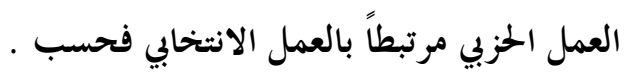
7. ان النخب السياسية لم تعمل على مأسسة الظاهرة السياسية العراقية لسلطاقا

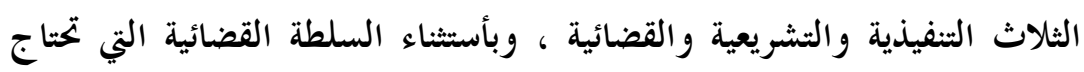

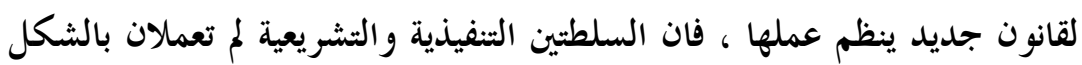
الذي يعزز ويرسخ من انماط ثقافة سياسية مدنية تعتمد المواطنة . 
فالسلطة التنفيذية تتشكل بعد صراع مرير حول الاستحقاق الانتخابي او الكتلة

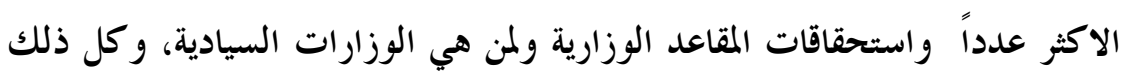
يحصل في وسائل الاعلام التي تزيد من الفجوة ما بين السلطة التنفيذية والمواطنين .

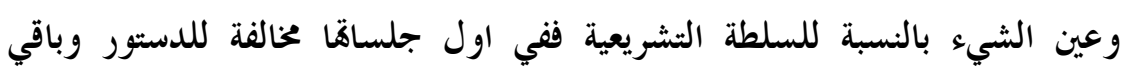
جلساتا الاخرى تصارع على اللجان و الرئاسات .

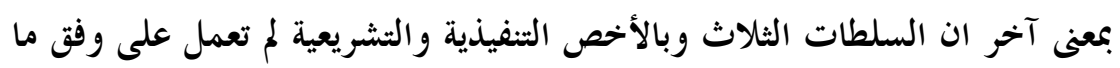
جاء في الدستور ، وهي كأنما ليست مؤسسات دولة، بل مؤسسات عائلية وشخصية.

V. ان الصراع ما بين اتجاه ممارسة الهيمنة والمركزة (المركزية) من النخب السياسية

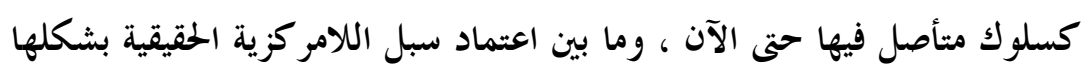

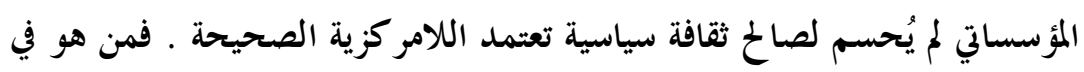

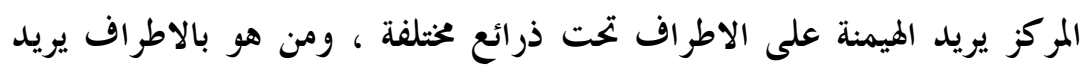
التحرر من الهيمنة ولكنه في الوقت نفسه يتبع المركزية في سلو كه ازاء المؤسسات

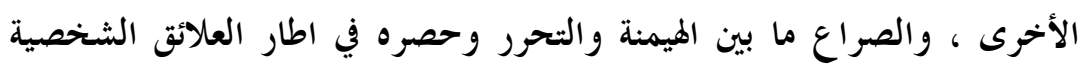

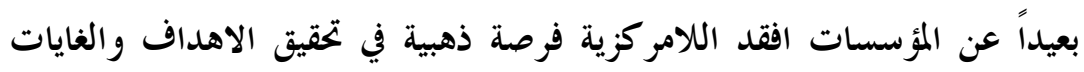
المرجوّة التي من اجلها تم اعتماد سبل اللامركزية . الخاتمة :

- - ان التشريعات الدستورية والقانونية المنظّمة لعمل اللامركزية الادارية لا تكفي

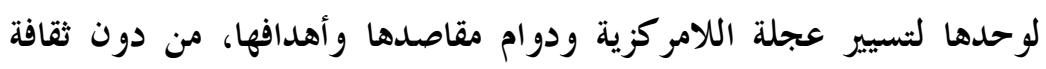

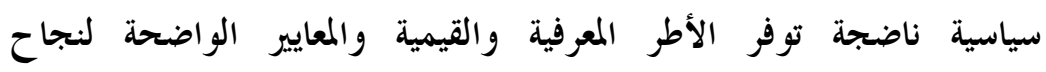

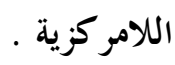

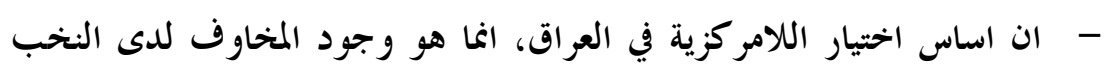

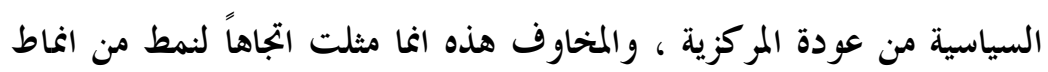

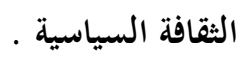


- - ان تطبيق اللامركزية كانت مقاصده توفير الحلول للمشاكل الموجودة او تلك

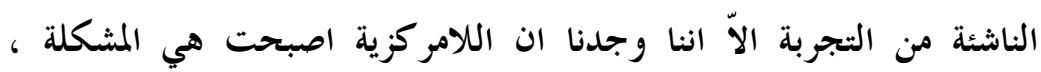
ونقصد التطبيق الخاطئ للامركزية ، وليس اللامركزية بحد ذاهما ، و وتتحمّل

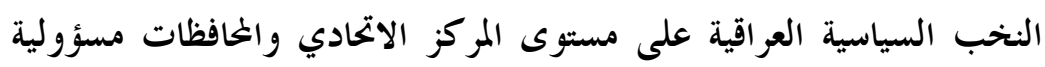

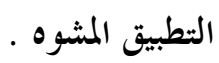

- - ان ارتباط اللامركزية بالخاصصة والتوافقية والإصرار عليها في الممارسات

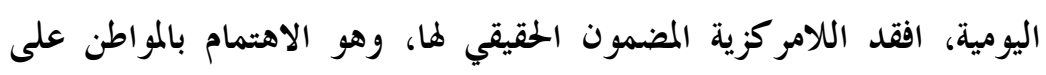
المستوى الخلي وتحقيق التنمية والاستقرار والانجاز .

- - هناك تناقض واضح في السلوك السياسي للنخب السياسية في التعامل مع مع دئ

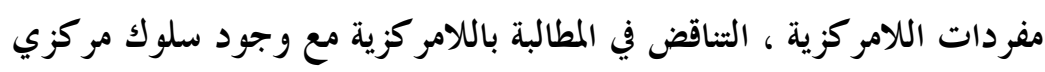

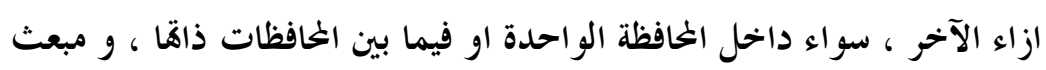

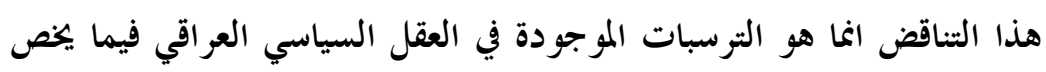

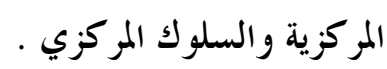

- - مازال هناك خلط ما بين اللامركزية السياسية (الفدرالية) واللامركزية الادارية

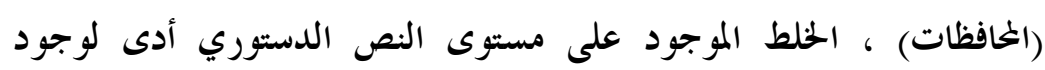
مشاكل حقيقية في تطبيق اللامركزية .

- - مازالت الثقافة السياسية للنخب السياسية بعيدة عن مقومات الثقافة الدستورية

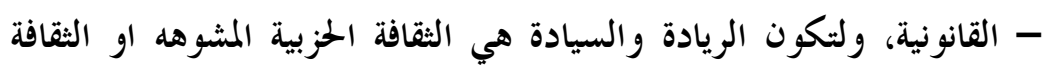

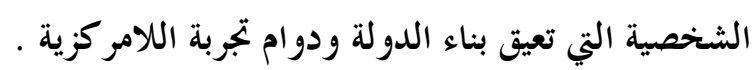

- - مل تصل الثقافة السياسية العراقية المى مواصفات الثقافة المشاركة او المساهمة

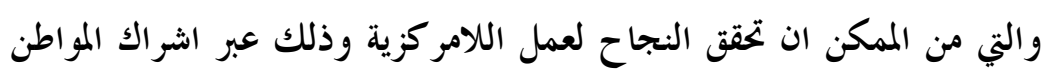

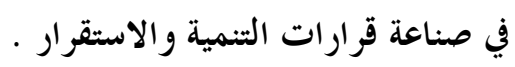

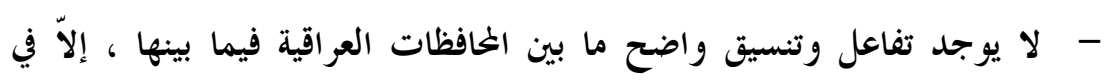

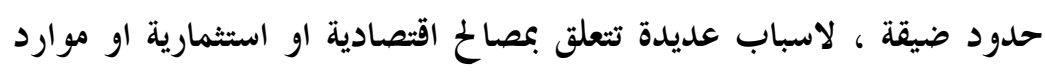


وثروات او تحديد الحدود الادارية ، وغياب هذا التفاعل والتعاون و التنسيق من شأنه ان يهدد استقرار تجربة اللامر كزية . - - رغم توافر النص القانولي الذي يتيح لبجلس النواب الرقابة على اعمال مجالس

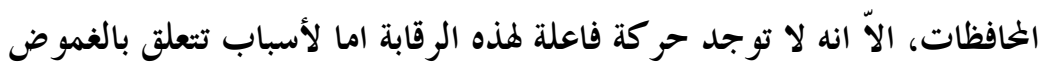

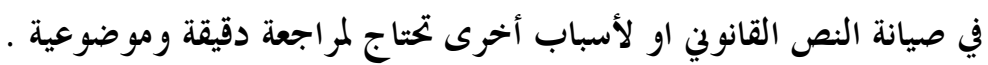
- - اخفق المركز الاتحادي في التعامل مع اللامركزية ومجالس الخحافات العراقية

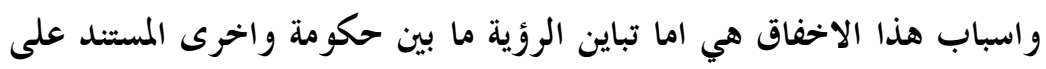

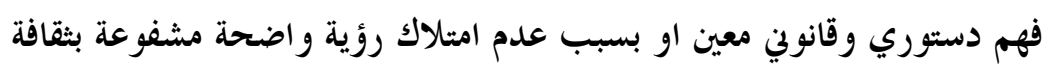

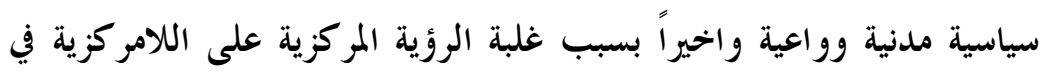
التعامل. - - لقد تعالّت مجالس الخافظات على المركز الاتحادي بالاستناد لنص دستوري غامض او صياغة خاطئة لمادة قانونية او بسبب الهيمنة للقوى الحزبية في

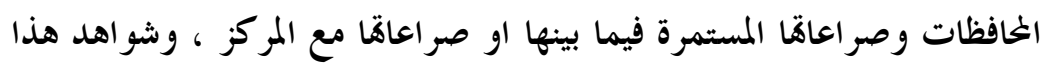
التعالي كثيرة، الامر الذي ادى لاختلال العلاقة ما بين حدود المركزية

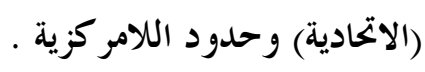

- ان - انقل الصلاحيات الواسعة للمحافظات لم يحّل المشكلة التي تعاني منها

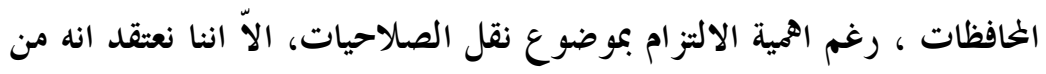

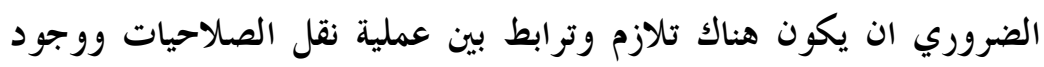

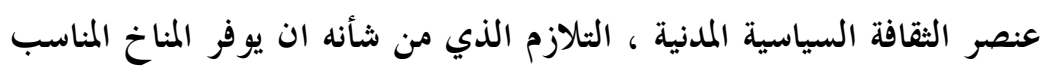
لعمل اللامر كزية .

- - ان التزاحم التشريعي على مستوى النص الدستوري والقوانين والتعديلات

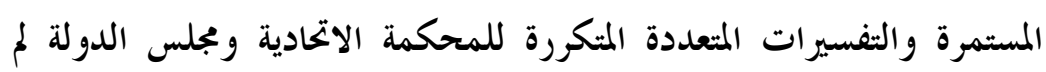

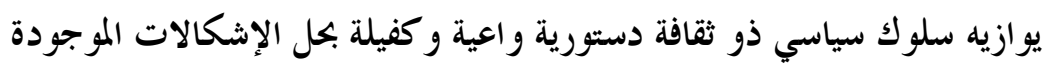


في النطبيق، لا بل ان ديمومة التصارعات المثكررة والمتشاهة في الخافظات سيضعف من رأي وتوجيه حكم المؤسسات القانونية والقضائية .

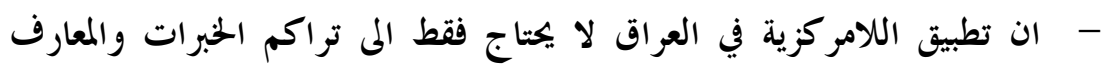

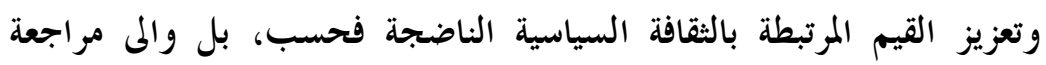

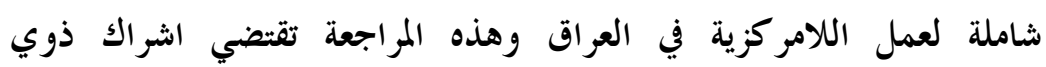

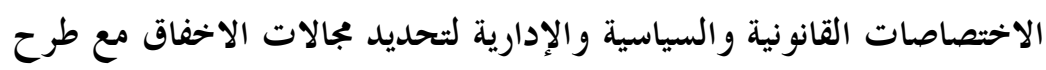

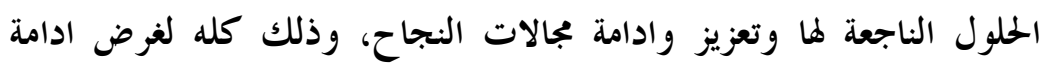

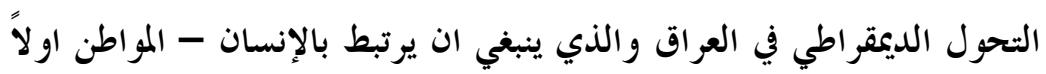
واخيراً.

\section{- Abstract}

- It sheds light on the cultural dimension in the decentralized administration experience in Iraq as evaluation tool by adding a new dimension in studying decentralization in addition to the administrative, political and legal dimensions .The proposal of study is that without the civil political culture ,the administrative decentralization in Iraq which remains weak and it may be imposed to a set of problems.

- The study includes an introduction, conclusion and a set of political and cultural issues, its components and it may have the political analysis of this culture and its role in determining the movement of the administrative decentralized movement in Iraq post 2003.

المصادر و الهو امش

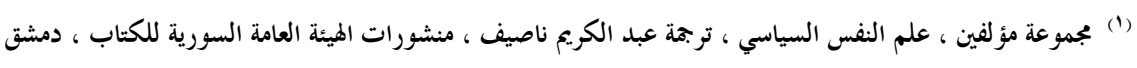

10ص، r...V.

${ }^{(2)}$ Edward B .Tylor, Primitive Culture Researches into the development of mythology religion language art and custom, VoL 1, London, John Murray, Fourth Edition Revised,1903,p1.

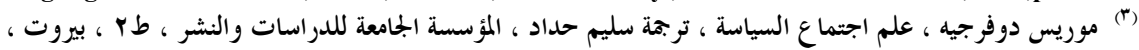

